AGUSTINA, José y LORENZO, Florencia."Sobre el confuso concepto de psicopatía en la jurisprudencia del Tribunal Supremo español: una revisión crítica ante los nuevos retos del Derecho penal de la peligrosidad".

Polít. crim. Vol. 11, No 21 (Julio 2016), Art. 4, pp. 66-103.

[http://www.politicacriminal.cl/Vol_11/n_21/Vol11N21A4.pdf]

\title{
Sobre el confuso concepto de psicopatía en la jurisprudencia del Tribunal Supremo español: una revisión crítica ante los nuevos retos del Derecho penal de la peligrosidad
}

\section{On the blurring concept of psychopathy in the Spanish Supreme Court jurisprudence: a critical review in the context of a Criminal Law focused on dangerousness}

\author{
Florencia Lorenzo García \\ Florencialorenzo29@hotmail.com \\ José R. Agustina \\ jragustina@uic.es \\ Universitat Internacional de Catalunya \\ Barcelona, España
}

\section{Resumen}

El presente artículo aborda desde una doble perspectiva la controversia suscitada en torno al concepto de psicopatía y su equivocidad, al ser utilizado por la jurisprudencia, con frecuencia, como término genérico equivalente a trastornos de la personalidad. Tras examinarse las primeras descripciones clínicas de tales constructos hasta llegar a los criterios diagnósticos actuales y que se reflejan en la jurisprudencia española, se analiza el proceso evolutivo en el tratamiento jurisprudencial de las (incorrectamente denominadas) psicopatías y su incidencia penológica en la responsabilidad criminal. Concretamente, se examina el desarrollo jurisprudencial relativo a la eximente "anomalía o alteración psíquica”, recogida en el art. 20.1 del vigente Código Penal, mediante una revisión de una muestra de 77 Sentencias de la Jurisdicción Penal dictadas por la Sala $2^{\text {a }}$ del Tribunal Supremo tras la entrada en vigor del Código Penal de 1995 (sentencias condenatorias dictadas entre febrero de 1998 y noviembre de 2010).

Más allá del propósito de tratar de zanjar la cuestión terminológica analizada y eliminar en lo posible la ambigua e indistinta utilización de los términos trastornos de la personalidad y psicopatías, el artículo se plantea tres objetivos: (1) aportar un análisis riguroso de las diferencias semánticas y las consecuencias prácticas de uno y otro término en los planos científico y jurídico; (2) ofrecer un estudio descriptivo de la utilización de dichas categorías en la jurisprudencia española; y (3) a partir de la evolución experimentada y de las nuevas tendencias en neurociencias, sugerir algunos retos de futuro para el Derecho penal, la Psicopatología forense y/o la Criminología ante el nuevo paradigma que se vislumbra frente a la expansión del denominado Derecho penal de la peligrosidad.

Palabras clave: Psicopatía, enfermedad mental, trastornos de la personalidad, anomalía o alteración psíquica, imputabilidad, Derecho penal de la peligrosidad. 
AGUSTINA, José y LORENZO, Florencia."Sobre el confuso concepto de psicopatía en la jurisprudencia del Tribunal Supremo español: una revisión crítica ante los nuevos retos del Derecho penal de la peligrosidad".

\begin{abstract}
The present paper analyzes from a double perspective the well-known controversy on psychopathy and personality disorders as Spanish jurisprudence uses the term psychopathy as equivalent to personality disorder in general. We examine the evolution of clinical constructs, its reflection on the Spanish jurisprudence and its implications on sentencing decision-making. In doing so, we review the application of the so-called "psychiatric anomalies or alterations" as an insanity defense (Article 20.1 of the Spanish Criminal Code) through a sample of 77 decisions of the Spanish Supreme Court (criminal convictions from February 1998 to November 2010).
\end{abstract}

Beyond the purpose of clarifying the terminological ambiguity on this matter, this paper addresses three main goals: (1) to provide a rigorous analysis on semantical and practical differences from scientific or legal realms; (2) to offer a descriptive study of the concrete application of such categories by Spanish criminal courts; and (3) to arise some reflections on the new challenges that a new Criminal Law focused on dangerousness is going to face and put such challenges in context with criminological and psychopathological issues in this field.

Key words: Psychopathy, mental illness, personality disorders, psychiatric anomalies and alterations, insanity defense, Criminal Law focused on dangerousness.

\title{
1. Introducción: sobre una necesaria (e inaplazable) clarificación conceptual y terminológica en los ámbitos científico y jurídico.
}

Como es sabido, la psicopatía no pertenece al núcleo de enfermedades mentales que han sido exhaustivamente investigadas y plenamente descritas por la ciencia médica. De hecho, tan solo muy recientemente ha logrado entrar en el catálogo recogido en el $\mathrm{DSM}^{1}$. Sin embargo, puede afirmarse que la psicopatía es una constante antropológica, presente en todas las épocas y culturas en un porcentaje estable entre la población -en torno a un 0,5 y un $1,5 \%$ de los varones-; y que su incidencia en la criminalidad es altamente significativa de un $15 \%$ a un $25 \%$ de la población reclusa está constituida por psicópatas-, hallándose la completa ausencia de empatía y frenos inhibitorios entre el conjunto de factores más relevantes relacionados con la inclinación al delito ${ }^{2}$.

${ }^{1}$ El DSM -por sus siglas en inglés, Diagnostic and Statistical Manual of Mental Disorders- es el manual
diagnóstico y estadístico de los trastornos mentales que tiene publicado la American Psychiatric Association
(APA). Contiene una clasificación de los trastornos mentales y proporciona descripciones de las categorías
diagnósticas, con el fin de que los clínicos y los investigadores de las ciencias de la salud puedan diagnosticar,
estudiar e intercambiar información y tratar los distintos trastornos mentales. La edición vigente es la quinta,
DSM-5, publicada el 18 de mayo de 2013 y solo muy recientemente traducida al español. El trastorno
antisocial de la personalidad se incluiría dentro del trastorno de la personalidad antisocial: 301.7 (F60.2).
${ }^{2}$ Véase, al respecto, la información y referencias de que da cuenta CANCIO MELIÀ, Manuel, "Psicopatía y
Derecho penal: algunas consideraciones introductorias", en: DEMETRIO CRESPO, Eduardo (Dir.),
MAROTO CALATAYUD, Manuel (Coord.), Neurociencias y Derecho penal. Nuevas perspectivas en el 
Polít. crim. Vol. 11, № 21 (Julio 2016), Art. 4, pp. 66-103.

[http://www.politicacriminal.cl/Vol_11/n_21/Vol11N21A4.pdf]

Muchas son las cuestiones que plantea esta suerte de daltonismo moral en que consiste la psicopatía. Entre las más relevantes se encuentra la del origen de esa incapacidad innata para el razonamiento moral. Tal y como se ha señalado, estas personas carecen de las estructuras neuronales normales, carencia que deriva en una indiferencia absoluta en el plano emocional, pese a que, desde la postura predominante, el sujeto comprende racionalmente qué está prohibido y qué no, y puede controlar perfectamente sus impulsos ${ }^{3}$. Sin embargo, ¿cuál es la causa de dicha indiferencia? ¿Es una indiferencia reprochable, es decir, libre? De este modo se abre paso la cuestión central en este ámbito: mad or bad? ${ }^{4}$

Desde siempre, aun admitiéndose una cierta disfuncionalidad o anormalidad en los psicópatas, éstos eran considerados como el prototipo de maldad. No es, pues, extraño que desde la perspectiva técnica del Derecho penal esta clase de delincuentes no merecieran -ni merecen hasta ahora, por regla general- ninguna consideración atenuatoria en la pena imponible, con algunas excepciones, como veremos infra.

Desde un punto de vista clínico, la psicopatía es una de las entidades más controvertidas en Psiquiatría, tanto en el plano conceptual como en el terminológico. Respecto del primero, existe un encendido debate desde hace ya dos siglos sobre la conveniencia de utilizar una categoría diagnóstica específica para los individuos que muestran dicho perfil caracteriológico y conductual, y también sobre cuáles deberían ser los elementos esenciales para definirla: la conducta, los rasgos de personalidad o una combinación de ambos. En cuanto al aspecto terminológico, el vocablo se ha utilizado -y se sigue utilizando- para describir entidades nosológicas y condiciones clínicas muy distintas ${ }^{5}$.

En cualquier caso, el término psicopatía en cuanto tal nunca ha sido recogido de forma explícita en las clasificaciones internacionales de las enfermedades mentales CIE y DSM ${ }^{6}$, utilizándose en cambio únicamente la denominación trastornos de la personalidad ${ }^{7}$.

ámbito de la culpabilidad y tratamiento jurídico-penal de la peligrosidad. Buenos Aires-Montevideo-Madrid: BdeF y Edisofer, 2013, p. 532 y ss.

${ }^{3}$ Para una exposición introductoria a la cuestión de la imputabilidad y el trastorno antisocial de la personalidad, véase CANO LOZANO, $\mathrm{M}^{\mathrm{a}}$ del Carmen, "Trastornos psicopatológicos relacionados con la imputabilidad”, en: SIERRA, J.C.; JIMÉNEZ, E .Ma y BUELA-CASAL, G. (Coords.), .Psicología forense: manual de técnicas y aplicaciones, $2^{a}$ ed., Madrid: Biblioteca Nueva, 2010, pp. 190-191.

${ }^{4}$ Vid. CANCIO MELIÀ, "Psicopatía y Derecho penal", cit. nota $n^{\circ} 2$, p. 536, donde trae a colación los trabajos de Litton y Morse, en los que se sostiene, respectivamente, que los psicópatas son agentes irracionales debido a su incapacidad para interiorizar valores, o que son personas a las cuales no se les puede dirigir un reproche.

5 TORRUBIA BELTRI, Rafael y CUQUERELLA FUENTES, Ángel, "Psicopatía: una entidad clínica controvertida pero necesaria en psiquiatría forense", Revista Española de Medicina Legal 34(1) (2008), p. 26.

${ }^{6}$ Las siglas CIE hacen referencia a la Clasificación Internacional de Enfermedades, en su $10^{\mathrm{a}}$ versión (CIE 10, Capítulo V: trastornos mentales y del comportamiento), elaborada por la Organización Mundial de la Salud (en la actualidad se encuentra en proceso de revisión para preparar la $11^{\mathrm{a}}$ versión); y por las siglas DSM se hace referencia al Manual Diagnóstico y Estadístico de los Trastornos Mentales, de la Asociación Americana de Psiquiatría, en su 5 $5^{\text {a }}$ versión (DSM-V, 2013 en inglés, 2014 en español), aunque tanto la jurisprudencia como la doctrina existentes hasta la fecha se refieren todavía a la versión anterior (DSM-IV-TR).

${ }^{7}$ Pero la denominación TP no se utiliza solamente para la psicopatía -que encajaría en el TP antisocial- sino que abarca todos los diferentes TP que hay definidos, debiendo tenerse en cuenta que algunos de ellos nada tienen que ver con la psicopatía. 
AGUSTINA, José y LORENZO, Florencia."Sobre el confuso concepto de psicopatía en la jurisprudencia del Tribunal Supremo español: una revisión crítica ante los nuevos retos del Derecho penal de la peligrosidad".

A pesar de que en el ámbito científico no se aceptara -ni plena, ni unívocamente- la utilización del término "psicopatía", lo cierto es que desde hace años en la jurisprudencia española se han venido utilizando indistintamente los términos psicopatías y trastornos de la personalidad, generándose una problemática confusión, a modo de sinécdoque, al confundirse la parte con el todo ${ }^{8}$. Esa confusión ha tenido efectos todavía más desorientadores si se tiene en cuenta que el trastorno antisocial de la personalidad o psicopatía no se ha venido a incluir -como se ha señalado supra-entre los trastornos de la personalidad del DSM hasta hace muy poco y que frente a dicha enfermedad mental de reconocimiento tardío la jurisprudencia ha mostrado cierta resistencia a la hora de asignarle cualquier efecto penológico positivo.

En el ámbito científico, por su parte, sigue existiendo todavía en la actualidad una falta de consenso notable en la definición de los distintos trastornos de la personalidad, afirmando un sector mayoritario de la Psiquiatría que los trastornos de la personalidad no son un grupo homogéneo bien definido, sino un "cajón de sastre" en el que se agrupan diversas tipologías de personalidad, caracterizadas por la conflictividad social, y que en estas personalidades subyace en general, una inmadurez afectiva y una base constitucional ligada al temperamento 9 .

No es de extrañar, pues, que como consecuencia de un debate científico todavía no resuelto tengamos en nuestro país una jurisprudencia vacilante, y a veces contradictoria, ligada al concepto de psicopatías como equivalente al de trastornos de la personalidad. Puede observarse, en todo caso, una clara evolución y un paralelismo innegable entre el progresivo reconocimiento científico de los trastornos de la personalidad y su tratamiento jurisprudencial.

Así, en un principio, la jurisprudencia venía negando a la psicopatía su reconocimiento como presupuesto fáctico atenuatorio de la pena, por no considerarla enfermedad mental. Sin embargo, constituyó un punto de inflexión la inclusión de la misma entre el listado de trastornos mentales y del comportamiento recogido en la Clasificación Internacional de Enfermedades mentales (CIE) elaborada por la $\mathrm{OMS}^{10}$. A partir de entonces, se generalizó en la doctrina jurisprudencial la aceptación de que los trastornos de la personalidad eran auténticas enfermedades mentales y, por consiguiente, podían tener alguna influencia en el

\footnotetext{
${ }^{8}$ El Diccionario de la Real Academia define esta figura retórica del siguiente modo: "Tropo que consiste en extender, restringir o alterar de algún modo la significación de las palabras, para designar un todo con el nombre de una de sus partes, o viceversa; un género con el de una especie, o al contrario; una cosa con el de la materia de que está formada, etc.".

9 Vid. ORTEGA MONASTERIO, Leopoldo, "Semiológica y aspectos médicos-legales de los grandes síndromes psicológicos", en: ORTEGA MONASTERIO et. al., Sicopatología Jurídica y Forense, Barcelona: PPU, 1991, pp. 19 y ss.

${ }^{10}$ Debe recordarse aquí que la inclusión de enfermedades en tales clasificaciones no debiera ir aparejado de ningún efecto directo en su aplicación en el ámbito de la psiquiatría forense, dado que su objetivo es meramente clínico y de investigación (y ya avisa el prólogo del DSM, por ejemplo, de los problemas de la aplicación de dichas clasificaciones a efectos jurídicos).
} 
Polít. crim. Vol. 11, № 21 (Julio 2016), Art. 4, pp. 66-103.

[http://www.politicacriminal.cl/Vol_11/n_21/Vol11N21A4.pdf]

juicio valorativo de la responsabilidad criminal. A este respecto, una sentencia marcó el cambio de tendencia jurisprudencial: la STS 1391/1988, de 29 de febrero ${ }^{11}$.

Posteriormente, la promulgación del Código Penal de 1995 supuso otro paso importante en materia de causas de inimputabilidad y, concretamente, en la cuestión que es objeto de análisis, al sustituirse en la formulación positiva de la eximente de responsabilidad criminal el concepto de "enajenado" (en el art. 8.1 del Código Penal de 1973) por el de "anomalía o alteración psíquica” (en el art. 20.1 del Código Penal de 1995). Con ello se podía dar cabida así, tanto a las anomalías de carácter patológico, como a las alteraciones de tipo psicológico (los trastornos de la personalidad).

En efecto, la redacción tan amplia que el Código Penal daba a partir de entonces al presupuesto de aplicación del art. $20.1 \mathrm{CP}$, al referirse a cualquier anomalía o alteración psíquica (duradera o transitoria), comportaba que pudiera tener cabida cualquiera de los trastornos mentales conocidos y clasificados por la psiquiatría, Y así es, lo que pasa es que para que sean consideradas circunstancias modificadoras de la responsabilidad criminal deben cumplir el resto del artículo 20.1 y los trastornos de la personalidad (incluido la psicopatía) no la cumplen. El cambio de paradigma era, en este sentido, enormemente significativo, pues el Código Penal anterior se refería al "enajenado", término que no definía una categoría psiquiátrica concreta, sino que era una expresión de lenguaje común aplicable a quien ha quedado «fuera de sí», y a quien, por tanto, sus actos, siéndole «ajenos», no se le podían imputar. La doctrina venía señalando que el término "enajenado" era poco apropiado, pues dentro del mismo era difícil abarcar, por ejemplo, el retraso mental, donde la persona no se ha enajenado, sino que, simplemente, no puede alcanzar el nivel normal de desarrollo de las facultades psíquicas (aunque la jurisprudencia siempre incluyera los casos de oligofrenias profundas en la eximente, seguramente forzando su tenor literal). Tampoco era fácil incluir en el término "enajenado" los casos de trastornos de personalidad y las neurosis, en los que la anormalidad que presenta el sujeto no comporta una «alienación» como sí sucede con las psicosis ${ }^{12}$.

Pues bien, como se puede inferir de todo lo anteriormente expuesto resulta del todo necesario zanjar la cuestión terminológica y eliminar en lo posible la ambigua e indistinta utilización de los términos trastornos de la personalidad y psicopatías. El presente trabajo trata de avanzar en esta línea mediante tres objetivos: (1) aportar un análisis riguroso de las diferencias semánticas y consecuencias prácticas de uno y otro término en los planos científico y jurídico; (2) ofrecer un estudio descriptivo de la utilización de dichas categorías en la jurisprudencia española; y (3) a partir de la evolución experimentada y de las nuevas tendencias en neurociencias, plantear algunos retos de futuro en el ámbito del Derecho penal, de la Psicopatología forense y de la Criminología.

\footnotetext{
${ }^{11}$ Para un extenso comentario a dicha sentencia, vid. SÁNCHEZ GARRIDO, Francisco, "El tratamiento jurisprudencial de la psicopatía", Revista de Derecho Penal y Criminología, $3^{\mathrm{a}}$ Época, no 7 (enero de 2012), pp. 347-366. Vid. también al respecto la STS de 22 de junio de 1988.

${ }^{12}$ Vid. Memento Penal 2011, núm. 2285.
} 
AGUSTINA, José y LORENZO, Florencia."Sobre el confuso concepto de psicopatía en la jurisprudencia del Tribunal Supremo español: una revisión crítica ante los nuevos retos del Derecho penal de la peligrosidad".

¿Cómo empezar a arrojar algo de luz para poner orden en un ámbito tan confusamente abordado en las últimas décadas, dando por resultado tan abundantes contradicciones terminológicas y semánticas?

El problema no solo puede achacarse a la comprensible falta de criterio diagnóstico por parte de los juristas, pues la doctrina psiquiátrica mayoritaria también ha venido realizando un uso indistinto de ambos términos. En concreto, existe un sector doctrinal mayoritario que por su sintomatología identifica la psicopatía con una modalidad concreta de trastorno de la personalidad: el trastorno disocial (CIE-10 F60.2) ${ }^{13}$ al incluir dentro del mismo las personalidades psicopáticas (si bien no las define) o el trastorno antisocial (DSM-V-TR F60.2 $)^{14}$. Por consiguiente, la denominación "psicopatías" se ha venido empleando en ambos mundos de forma no unívoca: en un sentido amplio, comprendiendo dentro de ella todos y cada uno de los trastornos de la personalidad; o en un sentido estricto, considerando propiamente psicópatas a aquellos sujetos que padecen un trastorno antisocial o disocial de la personalidad (a los que también se conoce como sociópatas) ${ }^{15}$.

En cuanto al segundo objetivo de este trabajo se presenta un estudio descriptivoretrospectivo del tratamiento jurisprudencial que reciben los trastornos de la personalidad (de forma abreviada, TP) mediante la revisión de 77 Sentencias dictadas por la Sala de lo Penal del Tribunal Supremo, en el periodo comprendido entre febrero de 1998 y noviembre de 2010, siendo de aplicación el Código penal vigente. Los TP que más incidencia tienen en la imputabilidad son el subtipo paranoide, límite, no especificado y antisocial, pero sin llegar a eximir la responsabilidad criminal. La importancia de la comorbilidad, apreciándose generalmente una eximente incompleta o una atenuante analógica de anomalía o alteración psíquica. La delitología de los TP s, predominando los delitos violentos. Y finalmente, haremos referencia a la pena o medida de seguridad con la que son castigados, constatándose que en las condenas por delitos cometidos por sujetos afectados por TP , el reconocimiento de dicho trastorno tiene una incidencia relativa en la pena, imponiéndose en su mitad inferior o, a la sumo rebajándose a la pena inferior en grado. La adopción de medidas de seguridad en casos de semi-imputabilidad del sujeto afecto a un $\mathrm{TP}$, es excepcional.

Y en relación al tercer propósito de este artículo, abordaremos algunas cuestiones a raíz de lo tratado y plantearemos algunos importantes retos en torno al Derecho penal de la peligrosidad. La relevancia práctica del estudio clínico y forense de la psicopatía y los trastornos de la personalidad se ha acentuado en los últimos años. En efecto, a todo lo que se acaba de señalar, se debe añadir el creciente interés que ha despertado el estudio de la

13 CIE-10, 10 $10^{\text {a }}$ edición de la Clasificación Internacional de las enfermedades. Geneva: World Health Organization, 1990.

${ }^{14}$ DSM-IV-TR, 4a edición revisada del Manual de Diagnóstico y Estadístico para los Trastornos Mentales. Washington; American Psychiatric Association, 2000.

15 Vid. CUELLO CONTRERAS, Joaquín, El Derecho Penal Español. Parte General. Nociones Introductorias. Teoría del delito (3 $\left.{ }^{\mathrm{a}} \mathrm{ed}\right)$, Madrid: Dikynson, 2002, p. 1012. 
imputabilidad penal desde las neurociencias y su impacto en el Derecho penal ${ }^{16}$. Así, no faltan voces que, sobre la base de los nuevos descubrimientos, si bien aún no confirmados, han apuntado que, al menos en algunos casos, la psicopatía eliminará la imputabilidad en un futuro no demasiado lejano ${ }^{17}$. Por ello, la posibilidad de atribuir, a una determinada estructura cerebral, las conductas desviadas de los psicópatas, en lugar de atribuírsela al sujeto, permitiría -según algunos autores-, separar a los psicópatas de su conducta y atribuir ésta a su falta de capacidad de sentir la infracción de la norma, siendo considerados inimputables en la comisión de aquellos delitos en los que exista una clara conexión entre la vivencia de la desviación de la norma penal y la infracción criminal y, por consiguiente, pudiendo ser sometidos a medidas de seguridad postdelictuales ${ }^{18}$.

\section{Marco previo: conceptos de psicopatía y trastorno de la personalidad.}

\subsection{Definición de psicopatía.}

La psicopatía, como ya hemos señalado, es una de las entidades clínicas más controvertidas en Psiquiatría, no existiendo un acuerdo unánime ni respecto a su denominación, ni acerca del constructo o definición de psicopatía.

El concepto de psicopatía tal y como lo entendemos en la actualidad es el resultado de la investigación que psiquiatras y psicólogos, europeos y americanos, han realizado durante siglos. Según Pichot ${ }^{19}$, es posible delimitar, a este respecto, tres desarrollos históricos parcialmente relacionados entre sí. El primero, basado en la idea de personalidad normal o anormal, definida por su adaptación o inadaptación social. El segundo, influido por la idea de degeneración mental, en relación a sujetos que podían ser antisociales o no, pero que presentaban de forma primaria una fragilidad en su personalidad y, como consecuencia, cierta predisposición a ciertos estados psicopáticos. Finalmente, el tercero se refiere al punto de vista de la escuela alemana, radicalmente distinto de los anteriores, pues está basado en la definición de tipos de personalidades anormales (personalidades psicopáticas), excluyendo cualquier referencia a la conducta antisocial en su definición.

La primera aproximación se realizó en el siglo XIX con las aportaciones del francés Pinel ${ }^{20}$ en su Traité de la mente, en donde acuñó el concepto de manía sin delirio como un trastorno de las funciones afectivas, siendo desarrolladas algunas de sus propuestas dentro del concepto de "monomanías". Posteriormente, Prichard ${ }^{21}$, en 1835, trataría el concepto de "locura moral", definida como un trastorno de las facultades morales.

\footnotetext{
${ }^{16}$ Vid., al respecto, DEMETRIO CRESPO, Eduardo (Dir.), MAROTO CALATAYUD, Manuel (Doord.), Neurociencias y Derecho penal. Nuevas perspectivas en el ámbito de la culpabilidad y tratamiento jurídicopenal de la peligrosidad. Buenos Aires-Montevideo-Madrid: BdeF y Edisofer, 2013.

${ }^{17}$ CANCIO MELIÀ, "Psicopatía y Derecho penal", cit. nota n², p. 532.

${ }^{18}$ CANCIO MELIÀ, "Psicopatía y Derecho penal", cit. nota n 2, p. 543

${ }^{19}$ PICHOT, P., "Psychopathic behaviour: a historical overview", en: HARE R.D., SCHALLING D. (Eds.), Psychopathic behaviour: Approaches to research, Chichester: John Wiley \& Sons (1978), pp. 55-70.

${ }^{20}$ PINEL, P., Traité médico-philosophique sur laliénation mentale, $2^{\mathrm{a}}$ ed., Paris: Brosson (1809).

${ }^{21}$ PRICHARD, J.C., A treatise on insanity and other disorders affecting the mind. London: Sherwood, Gilbert and Piper, 1835.
} 
AGUSTINA, José y LORENZO, Florencia."Sobre el confuso concepto de psicopatía en la jurisprudencia del Tribunal Supremo español: una revisión crítica ante los nuevos retos del Derecho penal de la peligrosidad".

El segundo desarrollo histórico tuvo lugar en 1888 con las aportaciones de Koch ${ }^{22}$, proponiendo el concepto de las llamadas inferioridades psicopáticas constitucionales. Años más tarde, en 1907, Kraepelin aportó una concepción clínica de las psicopatías, creando las denominadas personalidades psicopáticas y las diferencias de las psicosis ${ }^{23}$.

La tercera aproximación histórica al concepto de psicopatía tiene como referente la importante obra de Kurt Schneider de 1923 "Las personalidades psicopáticas”, creando la definición de psicópatas más conocida y utilizada. Según este autor "las personalidades psicopáticas son aquellas personalidades que sufren por su anormalidad o hacen sufrir, bajo ella, a la sociedad, distinguiendo hasta diez tipos diferentes de personalidades psicopáticas. Para este psiquiatra y sus contemporáneos, el criterio fundamental de las psicopatías es la ausencia de trastorno mental, es decir, la conservación intacta del estado mental del individuo psicopático.

Hasta entonces, el estudio de la psicopatía había quedado fuera del estudio médico científico por considerarlas trastornos de orden moral. Sin embargo, a mediados del siglo XX algunos autores empezaron a cuestionar esta opinión al considerar que las denominadas "alteraciones del carácter" podrían estar motivadas por una serie de factores de carácter biológico.

Ante esta nueva manera de entender la psicopatía, surgió la figura de Hervey Cleckley, quien realizó una exhaustiva descripción clínica de los rasgos de la personalidad del psicópata en su obra La máscara de la cordura (1941), obra que tuvo gran influencia en otros autores posteriores como Hare. Para Cleckley, el síntoma básico de la psicopatía sería "la deficiente respuesta afectiva hacia los demás, que explicaría el comportamiento antisocial que manifiesta el individuo", y propone como criterios para describir la psicopatía: (1) encanto externo y notable inteligencia; (2) inexistencia de alucinaciones y otras manifestaciones del pensamiento irracional; (3) ausencia de nerviosismo; (4) indigno de confianza; (5) mentiras e insinceridad; (6) falta de sentimiento de culpabilidad y vergüenza; (7) conducta antisocial sin aparente remordimiento; (8) razonamiento insuficiente y falta de capacidad para aprender de la experiencia vivida; (9) egocentrismo patológico e incapacidad para amar; (10) gran pobreza de reacciones afectivas; (11) pérdida específica de intuición; (12) irresponsabilidad en las relaciones interpersonales; (13) comportamiento fantástico; (14) amenazas de suicidio raramente cumplidas; (15) vida sexual impersonal, trivial y poco integrada; (16) e incapacidad para seguir cualquier plan de vida. Según este autor, al psicópata le falta la posibilidad de experimentar emociones y carece de ellas, aunque, en apariencia, se expresa de modo normal. Es lo que denominó demencia o afasia semántica, que implica que los psicópatas son incapaces de entender y

\footnotetext{
${ }^{22}$ Vid. RUBIO LARROSA, Vicente, Los trastornos de la personalidad. Sus tipos, (disponible en Internet: http://usuarios.discapnet.es/border/tlprubio.htm).

${ }^{23}$ FOMBELLIDA VELASCO, Luis, "Valoración médico-legal de los trastornos de la personalidad. Estudio Jurisprudencial”, Revista del Consejo general del Poder Judicial. Estudio Jurisprudencial, n40 (1995), p. 26.
} 
Polít. crim. Vol. 11, № 21 (Julio 2016), Art. 4, pp. 66-103.

[http://www.politicacriminal.cl/Vol_11/n_21/Vol11N21A4.pdf]

expresar el significado de experiencias emocionales, aun cuando puedan comprender el lenguaje.

A partir de 1952, con el origen de las clasificaciones internacionales de las enfermedades mentales CIE y DSM se introdujeron nuevas denominaciones y se establecieron categorías y criterios más científicos para llegar a un diagnóstico de estos trastornos. El CIE-10 ${ }^{24}$ utiliza la denominación trastorno disocial y el DSM-IV-TR ${ }^{25}$ trastorno antisocial de la personalidad, para referirse aproximadamente a los mismos fenómenos.

En la actualidad, se han llevado a cabo importantes estudios de los psicópatas, siendo fundamentales las aportaciones de Robert Hare, creador del PCL-R (1991) Psychopathy Checklist Revised, prueba que actualmente se ha estandarizado como método para diagnosticar la psicopatía, en la que se incluyen dos factores que conforman la psicopatía:

\begin{tabular}{|c|l|}
\hline Factor I. Personalidad & Factor II. Desviación Social \\
\hline 1. Locuacidad /encanto superficial & 3. necesidad de estimulación \\
2. Grandioso sentimiento de auto & 9. Estilo de vida parásito \\
valía & 10. Escaso autocontrol \\
4. Mentira patológica & 12. Precocidad \\
5. Manipulador & 13. Sin metas realistas \\
6. Falta de remordimiento/culpa & 14. Impulsividad \\
7. Afecto superficial & 15. Irresponsabilidad \\
8. Crueldad/falta de empatía & 18. Delincuencia Juvenil \\
16. No acepta responsabilidad de sus & 19.Revocación de la libertad condicional \\
actos & \\
\hline Items adicionales que no pertenecen a & \\
los factores & \\
\hline $\begin{array}{l}\text { 11. Conducta sexual promiscua } \\
\text { 12. Muchas relaciones maritales breves }\end{array}$ \\
13. Versatilidad delictiva
\end{tabular}

Este autor describe al psicópata como

"un depredador de su propia especie que emplea el encanto personal, la manipulación, la intimidación y la violencia para controlar a los demás y para satisfacer sus propias necesidades egoístas. Al faltarle la conciencia y los sentimientos que le relacionan con los demás, tiene la libertad de apropiarse de lo que desea y de hacer su voluntad sin reparar en los medios y sin sentir el menor atisbo de culpa o arrepentimiento" 26 .

\footnotetext{
${ }^{24}$ CIE-10, $10^{\text {a }}$ edición revisada de la Clasificación Internacional de las Enfermedades. Geneva, World Health Organization, 1990.

25 DSM-IV-TR, 4a edición revisada del Manual de Diagnóstico y Estadístico para los Trastornos Mentales. Washington, American Psychiatric Association, 2000.

26 HARE, Robert D., "La naturaleza del psicópata: algunas observaciones para entender la violencia depredadora humana", en: RAINE, A. y SAN MARTÍN, J. (Eds.), Violencia y psicopatía, 2aed., Barcelona: Ariel, 2002, pp. 15 y ss.
} 
AGUSTINA, José y LORENZO, Florencia."Sobre el confuso concepto de psicopatía en la jurisprudencia del Tribunal Supremo español: una revisión crítica ante los nuevos retos del Derecho penal de la peligrosidad".

Finalmente, la jurisprudencia, siguiendo la línea más influyente en psiquiatría, define la psicopatía como aquellos

"trastornos de la personalidad que se caracterizan por su marcado déficit de carácter y emocional que afecta a su modo de ser y a su temperamento, pero que no comprometen la capacidad de comprender y de querer del sujeto, puesto que su raciocinio y libertad de decisión permanecen intactos, y únicamente cuando su intensidad o profundidad son magnas, o se presentan asociadas a otras enfermedades de mayor fuste o entidad, podrán determinar, en su caso, una merma o disminución, en sus facultades cognitivas o volitivas y, en último término, una limitación más o menos grave de su capacidad de autodeterminación" (véase, STS de 17 de mayo de 1991).

\subsection{Concepto de trastorno de la personalidad y subtipos.}

Como ya hemos apuntado, la definición de trastorno de la personalidad es objeto de constante debate científico, no existiendo consenso sobre el mismo, llegando a afirmar un sector mayoritario de la psiquiatría que se trata de un "cajón de sastre",27.

Para Millón (1981) los trastornos de la personalidad pueden ser considerados como representaciones de desviaciones exageradas y patológicamente distorsionadas, emanadas de una distribución de rasgos normales y saludables, y no como la intromisión de alguna fuerza externa extraña sobre la personalidad del individuo. De esta manera, podríamos representar la personalidad y sus trastornos en una continuidad: Normal Disfunción, Leve, Moderada, Grave ${ }^{28}$.

La jurisprudencia considera los trastornos de la personalidad como

"un patrón duradero de conductas y experiencias internas que se desvía marcadamente de lo que cultural o socialmente se espera de la persona, es decir, de lo que constituye el patrón cultural de conducta, y que se manifiesta en el área de la cognición, en el de la afectividad, en el del funcionamiento interpersonal o en el del control de los impulsos (al menos en dos de dichas áreas). Se trata de un patrón de conducta generalmente inflexible y desadaptativo en un amplio rango de situaciones personales y sociales, que conduce a una perturbación clínicamente significativa o a un deterioro social, ocupacional o de otras áreas del comportamiento. El patrón es estable y de larga duración y su comienzo puede ser rastreado, por lo menos, desde la adolescencia o la adultez temprana. No puede ser interpretado como una manifestación o consecuencia de otro trastorno mental y no se debe al efecto psicológico directo de una sustancia

\footnotetext{
${ }^{27}$ Sobre el concepto de psicopatía versus trastorno de la personalidad, vid., LÓPEZ MIGUEL, María José y NUÑEZ GAITÁN, María del Carmen, "Psicopatía versus trastorno antisocial de la personalidad", Revista Española de Investigación Criminológica, Artículo 1, Número 7 (2009).

${ }^{28}$ MILLON, T., DAVIS, R.D. et al., Trastornos de la personalidad: más allá del DSM-IV (1 ${ }^{\mathrm{a}}$ ed., reimpr.), Barcelona: Masson, 2004, p.11.
} 
Polít. crim. Vol. 11, № 21 (Julio 2016), Art. 4, pp. 66-103.

[http://www.politicacriminal.cl/Vol_11/n_21/Vol11N21A4.pdf]

(por ejemplo, drogas de abuso, medicación o exposición a tóxicos), ni a una situación médica general (por ejemplo, trastorno craneal)" (STS 1363/2003, de 22 de octubre).

En el DSM-IV-TR (APA, 2000) se describen los rasgos de personalidad como patrones persistentes de formas de percibir, relacionarse y pensar sobre el entorno sobre uno mismo, que se ponen de manifiesto en una amplia gama de contextos sociales y personales. Plantea además que los rasgos de personalidad solo constituyen trastornos cuando son inflexibles y desadaptativos y cuando causan un deterioro funcional significativo o un malestar subjetivo. Añade, asimismo, que el diagnóstico de estos trastornos requiere una evaluación de los patrones de actividad del sujeto a largo plazo y las características particulares de la personalidad han de estar presentes desde el principio de la edad adulta ${ }^{29}$.

En la actualidad, para clasificar los trastornos de la personalidad se utilizan los sistemas diagnósticos de mayor aceptación entre los especialistas de la salud mental: la décima Clasificación Internacional de las Enfermedades (CIE-10) de la Organización Mundial de la Salud (OMS), y la quinta edición del Manual diagnóstico y estadístico de los trastornos mentales (DSM-V) de la Asociación Psiquiátrica Americana (APA) ${ }^{30}$.

La APA, en su DSM-IV-TR (pp. 765 y ss.), clasifica los trastornos de la personalidad en tres grupos, especificando la frecuencia con la que los diversos rasgos de la personalidad se entremezclan en un mismo individuo, haciendo que tales trastornos no sean compartimentos estancos. Admite los siguientes tipos de trastornos de la personalidad en la persona adulta:

Clasificación DSM-IV-TR de los trastornos de la personalidad

\begin{tabular}{|l|l|l|}
\hline GRUPO A & GRUPO B & GRUPO C \\
\hline Excesivamente & Excesivamente & Excesivamente Ansiosos y \\
Introvertidos, Raros y & Extrovertidos, & Apocados \\
Excéntricos & Emocionales, Impulsivos e & \\
& Inestables & \\
\hline *Trastorno PARANOIDE & *Trastorno HISTRIÓNICO & *Trastorno de la \\
de la personalidad & de la personalidad & personalidad \\
* Trastorno ESQUIZOIDE & *Trastorno LÍMITE & por EVITACIÓN \\
de la personalidad & (BORDERLINE) de la & Trastorno de la \\
*Trastorno & personalidad & personalidad por \\
ESQUIZOTIPICO de la & * Trastorno NARCISISTA & DEPENDENCIA \\
personalidad & de la personalidad & *Trastorno OBSESIVO- \\
& *Trastorno ANTISOCIAL & COMPULSIVO de la \\
de la personalidad & personalidad \\
& \multicolumn{2}{|l}{ Trastorno de la } \\
& \multicolumn{2}{|l}{} \\
\hline
\end{tabular}

\footnotetext{
${ }^{29}$ DSM-IV-TR, cit. nota ${ }^{\circ} 25$, pp. 769-770.

${ }^{30}$ Debido a que la traducción al español es de fechas muy recientes, nos referiremos en adelante a la $4^{\mathrm{a}}$ ed.
} 
AGUSTINA, José y LORENZO, Florencia."Sobre el confuso concepto de psicopatía en la jurisprudencia del Tribunal Supremo español: una revisión crítica ante los nuevos retos del Derecho penal de la peligrosidad".

\begin{tabular}{|l|l|l|}
\hline & & NO ESPECIFICADO \\
\hline
\end{tabular}

Otros trastornos de la personalidad

1. Trastorno pasivo-agresivo de la personalidad

2. Trastorno depresivo de la personalidad

3. Trastorno auto-destructivo de la personalidad

4. Trastorno sádico de la personalidad

La Clasificación de la CIE $10^{31}$ de la OMS comprende los siguientes tipos:

Clasificación de la CIE 10 de los trastornos de la personalidad

\begin{tabular}{|l|}
\hline F60-69 Trastornos de la personalidad y del comportamiento del adulto \\
\hline F60.0 Trastorno PARANOIDE de la personalidad \\
\hline F60.1 Trastorno ESQUIZOIDE de la personalidad \\
\hline F60.2 Trastorno DISOCIAL de la personalidad \\
\hline F60.3 Trastorno de INESTABILIDAD EMOCIONAL de la personalidad \\
\hline F60.4 Trastorno HISTRIÓNICO de la personalidad \\
\hline F60.5 Trastorno ANANCÁSTICO de la personalidad \\
\hline F.60.6 Trastorno ANSIOSO (con conducta de evitación) de la personalidad \\
\hline F60.7 Trastorno DEPENDIENTE de la personalidad \\
\hline F60.8 OTROS TRASTORNOS ESPECÍFICOS de la personalidad \\
\hline F60.9 Trastornos de la personalidad SIN ESPECIFICACIÓN \\
\hline
\end{tabular}

De los diferentes trastornos de personalidad, únicamente haremos un breve apunte del trastorno disocial ya que es el único que puede encajar en el concepto de psicopatía y, por ser el de mayor interés jurídico y forense. De hecho, son los trastornos de la personalidad que más alarma social generan ${ }^{32}$, además de apreciarse en gran parte de los delincuentes habituales $^{33}$ y ser considerados por un sector de la doctrina como los auténticos psicópatas (psicopatía en sentido estricto). La clasificación Internacional DSM-IV-TR lo califica como trastorno antisocial de la personalidad, y en la actualidad se les denomina "sociópatas".

Estos sujetos presentan problemas en tres vertientes a la vez: relaciones con los demás, afectividad y conducta. Presentan básicamente dos tipos de rasgos. El primero incluye el área emocional o interpersonal, es decir, aquellos atributos personales que hacen que el sujeto se desentienda de su componente más básicamente humano, resultando egocéntrico, manipulador, mentiroso y cruel. El segundo se remite a un estilo de vida antisocial y

\footnotetext{
${ }^{31}$ CIE10, $10^{\text {a }}$ edición, pp. 245 y ss.

${ }^{32}$ CUELLO CONTRERAS, El Derecho Penal Español, cit. nota n ${ }^{\circ} 15$, p. 1012.

${ }^{33}$ CEREZO MIR, José, Curso de Derecho Penal español. Parte General, III. Teoría Jurídica del delito/2, $1^{\text {a }}$ ed., Madrid: Técnos, 2005, p. 63.
} 
agresivo, donde lo importante es sentir tensión y excitación, sin más horizonte que el actuar por capricho o arrebato $^{34}$. Y se caracterizan principalmente por su desprecio hacia las normas establecidas por la sociedad. Carentes de principios morales, solo valoran a las demás personas en la medida en que pueden serles de alguna utilidad práctica, de modo que no tienen reparo alguno en atropellar los derechos ajenos cuando éstos representan un obstáculo para el logro de sus propósitos ${ }^{35}$.

Del concepto y evolución de los denominados trastornos de la personalidad, se deduce, por un lado, que bajo dicha denominación se agrupan muy diversas entidades y situaciones clínicas (así, las anomalías del carácter, las personalidades anormales y las personalidades psicopáticas y sociopáticas, etc.), en todas las cuales el carácter y el temperamento es algo substancial; y, de otro, que dichos trastornos parecen tener una base congénita sobre la que actúan, con mayor o menor intensidad, los factores ambientales y culturales ${ }^{36}$.

\section{Sobre el tratamiento jurisprudencial de los trastornos de la personalidad y la nueva medida de libertad vigilada posterior a la ejecución de la pena.}

\subsection{La culpabilidad e inimputabilidad del delincuente con trastorno de la personalidad.}

Como es sabido, de conformidad con lo establecido en el Código Penal la jurisprudencia viene señalando que para que un sujeto que comete un ilícito penal sea imputable se requieren dos elementos: a) capacidad de comprender lo injusto del hecho y b) capacidad de dirigir la actuación conforme a dicho entendimiento.

El primero de ellos (elemento intelectivo o cognoscitivo) supone que el sujeto tiene capacidad para valorar la licitud o ilicitud de un hecho, esto es, para comprender que un determinado comportamiento (realizado con consciencia y voluntad) es ilícito, es contrario a Derecho. El segundo (elemento volitivo) hace referencia a la capacidad para actuar conforme a esa comprensión, a la posibilidad que tiene el sujeto de dirigir su actuación de acuerdo con dicho entendimiento, o lo que es lo mismo, a la capacidad del individuo para manejar su voluntad y encaminarla al cumplimiento de lo dispuesto por el Derecho ${ }^{37}$.

El Código Penal vigente, en el párrafo primero del número $1^{\circ}$ de su art. 20 , declara exento de responsabilidad criminal al sujeto "que al tiempo de cometer la infracción penal, a causa de cualquier anomalía o alteración psíquica, no puede comprender la ilicitud del hecho o actuar conforme a esa comprensión”.

\footnotetext{
${ }^{34}$ GARRIDO GENOVÉS, Vicente, El psicópata: un camaleón en la sociedad actual, $7^{\mathrm{a}}$ ed., Valencia: Algar, 2005 , p. 36.

${ }_{35}$ BELLOCH FUSTER, A., SANDIN, B. y RAMOS, F, Manual de psicopatología, Madrid: McGraw-Hill, DL, 2002, p. 632.

${ }^{36}$ CARRASCO GÓMEZ, J. J., Trastornos de la Personalidad. Concepto. Clasificación de la OMS (I.C.D.X) y consideraciones médico forenses. Cuadernos de Derecho Judicial. Medicina Legal, Consejo General del Poder Judicial, Madrid, 1993, p. 364.

${ }^{37}$ MIR PUIG, Santiago, Derecho Penal. Parte General, 6a ed., Madrid: Ed. Reppertor, 2002, pp. 550-551.
} 
AGUSTINA, José y LORENZO, Florencia."Sobre el confuso concepto de psicopatía en la jurisprudencia del Tribunal Supremo español: una revisión crítica ante los nuevos retos del Derecho penal de la peligrosidad".

Por contraste, el Código Penal anterior empleaba una fórmula biológica (el art. $8.1^{\circ}$ del CP se limitaba a referirse al enajenado), si bien la jurisprudencia exigía que, además de la enajenación, concurriera el efecto psicológico de imputabilidad en el hecho concreto, dando lugar en la práctica a una fórmula mixta bilógico-psicológico (véase, entre otras, la STS de 21 de octubre de 1988). El actual art. $20.1^{\circ}$ ha adoptado la fórmula mixta biológicopsicológica que requiere, para la apreciación de la inimputabilidad, por una parte, que concurra una anomalía o alteración psíquica (base biológica) y, por otra, que ésta sea la causante de que el sujeto que la sufra no pueda comprender la ilicitud del hecho o actuar conforme a esa comprensión (base psicológica) en el momento de la comisión de un hecho ilícito.

Según Mir Puig, estos dos elementos son supuestos alternativos y excluyentes entre sí, en el sentido de que si el sujeto no fuera capaz de comprender la ilicitud del acto (o la omisión) que realiza, poco importa ya la consideración de sus facultades volitivas. Sólo si es comprendida la ilicitud del comportamiento desarrollado, debemos preguntarnos si el sujeto es capaz de actuar de conformidad con aquella comprensión ${ }^{38}$.

La utilización de la formula "cualquier anomalía o alteración psíquica”, configurada conforme a un sistema de numerus apertus, ha posibilitado la inclusión dentro de la misma tanto de enfermedades mentales, como de un conjunto residual de afecciones psíquicas que no tengan tal consideración ${ }^{33}$, permitiendo la inclusión de la psicopatía dentro de este supuesto de exención de responsabilidad: así lo ha entendido la Jurisprudencia, al incluir en el ámbito de esta circunstancia modificativa de la responsabilidad criminal los trastornos de la personalidad, considerando que estos trastornos satisfacen las exigencias del presupuesto biopatológico (STS de 1 de octubre de 1999; en el mismo sentido, SSTS de 3 de febrero 2009 y 25 noviembre 2009).

En el art. 8.1 ${ }^{\circ}$ del Código Penal anterior (de 1973), para la eximente de enajenación mental se exigía la existencia de enfermedad mental y, como quiera que la psicopatía no era considerada como tal, no entraba dentro de esta causa de exención de la responsabilidad criminal.

\subsection{Evolución de la jurisprudencia en relación a estas afecciones como enfermedad mental.}

La discusión científica sobre los distintos tipos de psicopatía se ha trasladado también al ámbito jurídico-penal, dando lugar a una jurisprudencia vacilante, y a veces contradictoria, sobre los efectos eximentes de la responsabilidad penal, que trataremos de clarificar.

El desarrollo histórico del concepto de psicopatía ha influido en la Jurisprudencia a la hora de interpretar la fórmula reguladora de la eximente de responsabilidad criminal aplicable según el Código penal vigente en cada momento. Sentado lo anterior, tres son las etapas en

\footnotetext{
${ }^{38}$ MIR PUIG, Derecho Penal. Parte General, cit. nota n 37, p. 556.
} 
Polít. crim. Vol. 11, № 21 (Julio 2016), Art. 4, pp. 66-103.

[http://www.politicacriminal.cl/Vol_11/n_21/Vol11N21A4.pdf]

la toma de posición del Alto Tribunal sobre la psicopatía. En una primera etapa, la psicopatía no tenía la consideración de enfermedad mental y, por consiguiente, el psicópata era responsable criminalmente. Posteriormente, la inclusión de las psicopatías entre los trastornos mentales en la novena revisión de la Clasificación Internacional de Enfermedades Mentales (CIE), realizada por la Organización Mundial de la Salud, conduce a un cambio de orientación en la Jurisprudencia, admitiendo ésta que las psicopatías constituyen una enfermedad mental y, por consiguiente, pueden afectar a la imputabilidad (STS de 29 de febrero de 1988). Y, finalmente, una tercera etapa, con la entrada en vigor del Código Penal de 1995, regulando como causa de exención de la responsabilidad criminal "cualquier anomalía o alteración psíquica", dentro de la cuales se da cabida a la psicopatía.

(i) El antecedente más remoto de la psicopatía en la jurisprudencia del Tribunal Supremo lo hallamos en la Sentencia de 17 de noviembre de 1886, identificándola con "manía sin delirio" (término acuñado por el médico francés Philipe Pinel para denominar estas conductas alteradas). Sin embargo, no será hasta la Sentencia de 10 de junio de 1935 en la que el Alto Tribunal califique al acusado como psicópata, a quien por tal circunstancia no le aplicó la eximente de "enajenación mental" del art. 8.1 ${ }^{\circ}$ del Código Penal. Esta resolución resultará también pionera a la hora de establecer los criterios a tener en cuenta para valorar si la psicopatía puede contemplarse como causa de exención o atenuación de la responsabilidad penal obligando "a acudir al examen en cada caso del sujeto mismo, de sus antecedentes, de las circunstancias de ocasión y lugar, y de las inmediatamente anteriores, simultáneas y subsiguientes al hecho", línea argumental que sigue vigente hoy día ${ }^{39}$.

A finales de 1981 cambiará su forma de entender la psicopatía hasta el momento y comenzará el Tribunal Supremo a considerarla una enfermedad mental, definiéndola como tal en multitud de ocasiones como:

"enfermedades mentales de carácter endógeno, que acompañan, a quien las padece, desde la cuna hasta el sepulcro", produciendo trastornos del temperamento y del carácter, así como reacciones vivenciales anómalas y que, de ordinario, no afectan ni a la capacidad de discernimiento del sujeto, ni a sus facultades de inhibición, autodominio o autocontrol, señalándose que, generalmente, ni eximen ni atenúan la responsabilidad, a menos que se presenten asociadas a otras dolencias mentales de mayor gravedad" (STS de 19 de diciembre de 1981).

Así pues, el tratamiento penal que iban a recibir los psicópatas era el mismo, sujetándose a responsabilidad criminal plena a menos que se presentasen asociadas con otras dolencias mentales de mayor gravedad. A partir de entonces, se alternarán las resoluciones que mantenían la línea interpretativa tradicional, de no considerar la psicopatía como enfermedad mental, con las que lo consideraban como tal ${ }^{40}$.

Son muchas las resoluciones del Alto Tribunal en las que, tras calificar la psicopatía como "desequilibrios caracterológicos, enfermedades de carácter endógeno, anormalidades

\footnotetext{
${ }^{39}$ SÁNCHEZ GARRIDO, "El tratamiento jurisprudencial de la psicopatía”, cit. nota n’ 11, p. 351.

${ }^{40}$ SÁNCHEZ GARRIDO, "El tratamiento jurisprudencial de la psicopatía”, cit. nota n 11, pp. 355-356.
} 
AGUSTINA, José y LORENZO, Florencia."Sobre el confuso concepto de psicopatía en la jurisprudencia del Tribunal Supremo español: una revisión crítica ante los nuevos retos del Derecho penal de la peligrosidad".

originadoras de trastornos de temperamento, de la afectividad, de la vida vegetativa, influyentes en la parte emocional del sentimiento y en el querer", declaran la irrelevancia penal de las personalidades psicopáticas por tratarse de sujetos que no padecen alteraciones mentales afectantes a inteligencia y voluntad, elementos básicos del juicio de culpabilidad. Añadiendo el Alto Tribunal, que esas personalidades tienen conocimiento de la Ley y voluntad de infringirla ${ }^{41}$. En otras resoluciones, el Tribunal Supremo aprecia la atenuante analógica de la eximente incompleta de enajenación mental, mostrando su razonabilidad ${ }^{42}$. Y, finalmente, otras resoluciones adoptan la tesis de la concurrencia de una eximente incompleta de enajenación mental, en diversas alteraciones psicopáticas, por detectación de una especial y profunda gravedad o de complementarias o aditivas anomalías orgánicas o psíquicas coexistentes, potenciador todo ello de la latente alteración del psiquismo, con manifiesta incidencia en el área de la imputabilidad.

En definitiva, se aprecia la eximente incompleta de enajenación mental, cuando junto con la psicopatía se aprecian otras anomalías orgánicas o psíquicas ${ }^{43}$.

(ii) Un hecho clave en el cambio de orientación doctrinal sobre la psicopatía será la inclusión de esta afección en la Clasificación Internacional de Enfermedades Mentales. De este cambio de orientación doctrinal es exponente fundamental -como ya se ha adelantado, la Sentencia de 29 febrero 1988, que justifica de forma explícita el motivo del cambio doctrinal operado respecto a la psicopatía, señalando lo siguiente: a) necesidad de sintonizar con la Novena Revisión de la Clasificación internacional de Enfermedades Mentales, realizada por la Organización Mundial de la Salud; b) conveniencia de abogar por el reconocimiento del psicópata como enfermo mental; c) comprensión de la psicopatía como enfermedad mental, de acuerdo con la interpretación dada por la doctrina al art. 8.1 del Código Penal de 1973), pudiendo ser más o menos relevante o absolutamente irrelevante, en la imputabilidad del sujeto, según la entidad de la merma que este experimente en sus facultades intelectivas y volitivas y finalmente; d) apreciación de la eximente incompleta de responsabilidad criminal de enajenación mental, cuando la personalidad psicopática se presenta asociada a otro tipo de disfunciones (el acusado presentaba intoxicación alcohólica y sobreexcitación por celos).

Como consecuencia del cambio de orientación doctrinal, el carácter de enfermedad mental de la psicopatía podrá ser, de acuerdo con la interpretación dada a la eximente de enajenación mental del art. 8.1 ${ }^{\circ}$ del Código Penal de 1973, irrelevante o más o menos relevante, según el grado de afectación a las facultades cognoscitivas o volitivas del sujeto. La Jurisprudencia, en resoluciones posteriores, vino a señalar lo siguiente: a) las

\footnotetext{
${ }^{41}$ Vid., entre muchas otras, SSTS de 4 abril 1984 (RJ 1984\2312), 13 junio 1985 (RJ 1985\3005), 18 de enero 1986 (RJ 1986\150) y 11 noviembre 1987 (RJ 1987\8496).

${ }^{4}$ Sentencias tales como las de 12 y 27 marzo 1985 (RJ 1985\1627 y RJ 1985\2035), 27 enero, 1 julio y 19 diciembre 1986 (RJ 1986\185, RJ $1986 \backslash 3869$ y RJ 1986\7968).

${ }^{43}$ Vid., la STS de 24 de noviembre de 1997, en la que se recoge un resumen jurisprudencial sobre el tratamiento de la psicopatía con anterioridad al Código Penal de 1995
} 
Polít. crim. Vol. 11, № 21 (Julio 2016), Art. 4, pp. 66-103.

[http://www.politicacriminal.cl/Vol_11/n_21/Vol11N21A4.pdf]

psicopatías no tienen su reflejo tasado e inmutable en la modificación de la responsabilidad criminal, que se deben ponderar en cada caso concreto, para determinar si se afectan a la inteligencia y voluntad del sujeto (STS de 17 de abril 1990); b) la anormalidad caracterológica del psicópata ha de estar en relación causal con el hecho delictivo (SSTS de 24 enero 1991 y 23 febrero 1993) y el tipo de delito ha de estar en relación con el tipo de psicopatía para que modifique la imputabilidad (STS de 6 febrero 1987); c) cuando las psicopatías ofrezcan una intensidad o profundidad graves o se presentan asociadas a otras enfermedades mentales de mayor fuste o entidad, pueden determinar, en su caso, una merma, disminución o aminoración de las facultades cognoscitivas o de las volitivas del sujeto y, en último término, una limitación, más o menos grave, de su capacidad de determinación (SSTS de 9 diciembre 1988, 24 enero 1991, 6 mayo y 9 junio 1992, 22 mayo y 14 octubre 1993 y 4 octubre 1994).

En resumen, del repaso de la Jurisprudencia se desprende este nuevo entendimiento de la psicopatía como enfermedad mental, salvo alguna excepción jurisprudencial que aún la considera "al margen por completo de las enfermedades" (STS de 14 de diciembre de 1990). Ahora bien, se sigue insistiendo en que, dada su

"muy variada sintomatología, hasta el punto de que algunos científicos han llegado a clasificar hasta once modalidades de personalidades psicopáticas existiendo, además, dentro de cada tipo, toda clase de combinaciones y situaciones intermedias, no se puede establecer una teoría general sobre la imputabilidad de los psicópatas" (STS de 5 de octubre de 1991) ${ }^{44}$.

(iii) Finalmente, el problema de la inclusión de la psicopatía en la eximente quedó resuelto, como ya hemos apuntado, con la redacción del art. 20.1 del Código Penal de 1995, empleando la formula biológica-psicológica de cualquier anomalía o alteración psíquica, y que vino a sustituir la formula enajenación mental, dando cabida a los trastornos de personalidad (psicopatías).

La jurisprudencia vino a exigir, para la exención completa o incompleta de la responsabilidad criminal, la doble concurrencia de un elemento biopatológico y, junto a él, de otro constituido, bien por la dificultad de comprensión por parte del sujeto respecto a la significación que tiene su comportamiento para el Derecho, bien por la ausencia o merma de su autonomía para determinarse en su conducta a resultas de aquella comprensión (STS 3 de febrero de 2009). Añadiendo que los trastornos de la personalidad o psicopatías (...) tienen encaje en el art. 20.1, pues se trata sin duda de anomalías o alteraciones psíquicas (STS núm. 2167/2002, de 23 de diciembre).

En cuanto a la relevancia de estos trastornos en la imputabilidad, tras la entrada en vigor del CP de 1995, se debe señalar que el Alto Tribunal se ha pronunciado de forma reiterada sobre esta cuestión, recordando en sus resoluciones que en la doctrina jurisprudencial la relevancia de los trastornos de la personalidad en la imputabilidad no responde a una regla general (STS núm.1363/2003, 22 de octubre). Lo cierto es que la doctrina

\footnotetext{
${ }^{44}$ Vid., la Sentencia de 16 de noviembre de 1999, en la que se recoge un resumen jurisprudencial sobre el tratamiento de la psicopatía con anterioridad al Código Penal de 1995.
} 
AGUSTINA, José y LORENZO, Florencia."Sobre el confuso concepto de psicopatía en la jurisprudencia del Tribunal Supremo español: una revisión crítica ante los nuevos retos del Derecho penal de la peligrosidad".

jurisprudencial los ha considerado en ocasiones irrelevantes, por estimar que en el caso concreto no se encontraba afectada dicha capacidad de conocimiento y voluntad, elementos básicos del juicio de imputabilidad. Por lo general, se han valorado penalmente como atenuantes analógicas y en trastornos de personalidad especialmente graves -generalmente asociados a otras patologías-, han sido valorados como eximente incompleta (STS 14 de mayo de 2001).

Esta cuestión será abordada más detalladamente infra, en la última parte de este artículo, tras la revisión de la muestra de 77 Sentencias dictadas por el Tribunal Supremo siendo ya de aplicación el CP de 1995.

\subsection{La nueva medida de libertad vigilada posterior a la ejecución de la pena.}

La cuestión del tratamiento aplicable a los psicópatas es uno de los problemas más importantes que se plantea en la práctica en torno a la respuesta penal a los trastornos de la personalidad. Un amplio sector de la doctrina considera que no hay otro problema similar en toda la Psiquiatría Forense -en que sea tan patente la necesidad de complementar una resolución punitiva con otras medidas-, y ello a causa de las características esenciales de estos sujetos anormales y de lo irreductible de su tratamiento ${ }^{45}$. La única vía técnicamente correcta parecería ser la determinada por las medidas de seguridad, que se constituyen como las consecuencias penales más apropiadas para los inimputables y, ocasionalmente, también para los sujetos con imputabilidad disminuida ${ }^{46}$.

En nuestra doctrina proliferaron -con ocasión o sin ella, por ejemplo, con motivo del Anteproyecto de reforma del Código Penal de 2008-, opiniones favorables a disponer de algo más que la pena para neutralizar la peligrosidad de los delincuentes peligrosos. Algunos autores abogaron ya entonces por medidas de seguridad para los delincuentes habituales peligrosos de criminalidad grave (internamiento en centros de terapia social o internamiento en centros de custodia) ${ }^{47}$; otros, por la adopción de medidas de seguridad privativas de libertad que complementen la pena ${ }^{48}$; y otros autores, como Leal Medina, habían ya solicitado con anterioridad el establecimiento de una medida de seguridad no privativa de libertad consistente en efectuar una vigilancia policial del psicópata, o bien, la

\footnotetext{
45 JIMÉNEZ DÍEZ, M. J. y FONSECA MORALES, G. M., Trastornos de la personalidad (psicopatías). Tratamiento científico y jurisprudencial, Madrid: CESEJ-ediciones, 2006, p. 115.

46 JIMÉNEZ DÍEZ/FONSECA MORALES, Trastornos de la personalidad (psicopatías), cit. nota $\mathrm{n}^{\circ} 45, \mathrm{p}$. 116.

47 CEREZO MIR, José, "Reflexiones críticas sobre algunas manifestaciones de la moderna tendencia a incrementar el rigor en la exigencia de responsabilidad criminal”, Revista Penal, núm. 22 (2008), p. 17.

${ }^{48}$ SILVA SÁNCHEZ, Jesús-María, "El contexto del anteproyecto de reforma del Código Penal de 2008", en: VV. AA., El Anteproyecto de modificación del Código Penal de 2008. Algunos Aspectos, Cuadernos Penales José María Lidón, núm.6, Bilbao, 2009, p. 25.
} 
Polít. crim. Vol. 11, № 21 (Julio 2016), Art. 4, pp. 66-103.

[http://www.politicacriminal.cl/Vol_11/n_21/Vol11N21A4.pdf]

sumisión a la vigilancia de la autoridad, ${ }^{49}$ que serviría para dar satisfacción a los supuestos en los que este tipo de delincuentes peligrosos, tras cumplir su condena, salieran de prisión $\mathrm{y}$, ante la alta probabilidad de comisión de futuros delitos, se les practicara un seguimiento personal para evitar su reincidencia.

A dichos postulados parece dar respuesta la nueva medida de seguridad de libertad vigilada introducida en la reforma del Código Penal, operada por LO 5/2010, de 22 de junio, al ser de aplicación también a los sujetos imputables, de forma acumulada y de ejecución posterior a la pena de prisión impuesta en Sentencia, si bien limitada en un principio, a dos tipos de delincuencia: la que atenta contra la libertad e indemnidad sexuales (Título VIII) y la relativa a las organizaciones y grupos terroristas y a los delitos de terrorismo (Capítulo VIII del Título XXII) ${ }^{50}$.

La reciente reforma del Código Penal operada por LO 1/2015, ha ampliado el ámbito de aplicación de la referida medida a todos los delitos contra la vida (Título I) y en los delitos de malos tratos y lesiones cuando se trate de víctimas de violencia de género y doméstica (Título II), si bien su imposición será de carácter facultativo ${ }^{51}$.

La regulación que de las medidas de seguridad se hace en nuestro Código Penal tiene su fundamento en "la peligrosidad criminal del sujeto" (art. 95 CP). Que se exija la peligrosidad criminal del sujeto supone abandonar el presupuesto indeterminado y confuso referido a la peligrosidad social que en el pasado sustentó nuestra legislación penal ${ }^{52}$. Dicha peligrosidad criminal viene así definida en el art. 95 del Código Penal y se refiere a un juicio de pronóstico, emitido por el juez o tribunal, acerca de la probabilidad o relevante posibilidad de que el sujeto pueda cometer nuevos delitos en el futuro. Dicha peligrosidad debe verificarse, en todo caso, tras la comisión de un hecho previsto como delito y debe atenerse a criterios de estricta necesidad, de forma que una medida nunca podrá exceder del límite de lo necesario para prevenir dicha peligrosidad, ni resultar más gravosa ni de mayor duración que la pena abstractamente aplicable al delito cometido. En relación a los inimputables, las medidas de seguridad sustituyen la pena, mientras que en los semiimputables actúan ocasionalmente como complemento de la misma-sistema vicarial-. En todo caso, las medidas de seguridad deberán sujetarse a un régimen de garantía semejante a la pena.

Como es sabido, las medidas de seguridad, según establece el art. 96.1 del Código Penal, pueden ser privativas y no privativas de libertad. Son medidas privativas de libertad: el internamiento en Centro psiquiátrico, el internamiento en Centro de deshabituación y el internamiento en Centro educativo especial (art. 96.2); y dentro de las no privativas de libertad, se encuentra la libertad vigilada (art.96.3), consistente según el art. 106 del Código Penal en el sometimiento del condenado a control judicial a través del

\footnotetext{
${ }^{49}$ LEAL MEDINA, J., "La psicopatía y su incidencia como anomalía psíquica en la doctrina del Tribunal Supremo. La interacción de los factores biológicos, genéticos y ambientales en el juicio de imputabilidad", Revista de Derecho y Proceso Penal, $\mathrm{n}^{\circ} 10$ (2003/2), p. 173.

${ }^{50}$ Vid. Art. 579 bis del CP (red. LO 2/2015, de 30 de marzo)

${ }^{51}$ Vid. Art. 140 bis y 156 ter del CP (red. LO 1/2015 de 30 de marzo)

52 TERRADILlOS BASOCO, J., Peligrosidad Social y Estado de Derecho, Madrid: Ed. Akal, 1981, p. 134.
} 
AGUSTINA, José y LORENZO, Florencia."Sobre el confuso concepto de psicopatía en la jurisprudencia del Tribunal Supremo español: una revisión crítica ante los nuevos retos del Derecho penal de la peligrosidad".

cumplimiento por su parte de alguna o algunas de las medidas que se relacionan (obligación de estar localizable, comunicar el cambio de residencia o del lugar o puesto de trabajo, prohibición de ausentarse de un determinado lugar, prohibición de aproximarse y comunicarse con la víctima, prohibición de acudir o residir en determinados lugares, prohibición de desempeñar determinadas actividades, obligación de participar en programas formativos, laborales, etc., y obligación de seguir tratamiento médico externo o someterse a un control médico periódico).

\section{Estudio de campo: muestra de sentencias analizadas.}

\subsection{Objetivos y metodología.}

Tras el estudio previo, una vez analizado el marco conceptual necesario nos disponemos ofrecer un análisis descriptivo de la utilización de dichas categorías en la jurisprudencia española.

Mediante el estudio de campo que se expone a continuación, se pretendía describir el tratamiento jurisprudencial que reciben la psicopatía y los trastornos de la personalidad en la jurisprudencia española. Y, en concreto, como objetivos específicos del estudio se pretendía obtener información sobre los siguientes extremos:

1-Los concretos trastornos de personalidad recogidos en la jurisprudencia.

2-Las repercusiones sobre la responsabilidad contemplada en dichas sentencias.

3-La repercusión en las consecuencias jurídicas del delito (penas y medidas de seguridad).

4-La interacción de los factores anteriores con a) comorbilidad de patología y b) hechos que se imputan.

Desde el punto de vista metodológico, se pudo realizar un estudio descriptivo retrospectivo del tratamiento jurisprudencial que reciben los trastornos de la personalidad mediante la revisión de las Sentencias del Tribunal Supremo dictadas con posterioridad a la entrada en vigor del Código Penal de 1995, hasta noviembre de 2010. Se han analizado 77 Sentencias dictadas por la Sala Segunda del Tribunal Supremo en recursos de casación, en el periodo comprendido de febrero de 1998 a noviembre de 2010: 70 de ellas lo han sido en recursos contra las Sentencias dictadas por las Audiencias Provinciales y 7, contra las sentencias dictadas por la Sala Civil y Penal de los Tribunales Superiores de Justicia de las Comunidades Autónomas. Todas las resoluciones analizadas habían sido publicadas en las compilaciones de Jurisprudencia, La Ley, EDJ y RJ, recogiendo las siguientes variables y habiéndose realizado un estudio descriptivo y analítico multivariable:

1-Identificación de la Sentencia. 2-Sala del Tribunal Supremo. 3-Órgano de procedencia del procedimiento. 4-Año de la sentencia. 5-Procedimiento de acceso al Tribunal Supremo. 6Hechos imputados. 7-Diagnósticos que se dan por probados. 8-Relación que se establece con los hechos. 9-Afectación reconocida de la responsabilidad. 10-Pena, recogiendo la posible reducción de la misma. 11-Medidas de seguridad. 
Polít. crim. Vol. 11, № 21 (Julio 2016), Art. 4, pp. 66-103.

[http://www.politicacriminal.cl/Vol_11/n_21/Vol11N21A4.pdf]

\subsection{Resultados.}

A continuación se detallan los resultados obtenidos tras la revisión de la muestra de 77 sentencias y se procede a exponer los datos correspondientes a la relación entre los distintos tipos de trastornos de personalidad reconocidos en las mismas y el resto de variables de este estudio: relación con el delito cometido, su incidencia en la imputabilidad y en las consecuencias jurídicas del delito (penas y medidas de seguridad).

Las 77 sentencias analizadas son condenatorias por los siguientes delitos: asesinato u homicidio (38), lesiones graves (10), agresiones sexuales (15), robo (23), contra la salud pública (13) y por otros delitos (22). Cabe referenciar que 28 de las sentencias son condenatorias por más de un delito.

De los diagnósticos que se dan por probados en las referidas sentencias, los TP específicos o en comorbilidad con otros trastornos son los siguientes: 47 se corresponden con el Cluster de TP específico, 7 TP paranoide, 3 esquizoide, 20 antisocial, 1 narcisista, 14 límite y 2 obsesivo-compulsivo. En 16 sentencias se dan por probados TP no especificados y en las 14 restantes, trastornos mixtos de la personalidad.

La Tabla I recoge la frecuencia de los TP agrupados por cluster: en un $13 \%$ con el Cluster A, en un $45 \%$ con el Cluster B y en un $3 \%$ con el Cluster C; incluidos los TP no especificados $21 \%$, TP mixto $18 \%$ y los supuestos de comorbilidad con otros trastornos más severos (CI límite y esquizofrenia) que representan un 4\%, del total de las sentencias analizadas.

Tabla I: Frecuencia de los TP (agrupados por clústeres) en las sentencias analizadas ${ }^{53}$

Cluster Subtipo TP N (\%) N (\%)

\begin{tabular}{|c|c|c|c|}
\hline \multirow{3}{*}{ A } & Paranoide & $7(9 \%)$ & \multirow{3}{*}{$10(13 \%)$} \\
\hline & Esquizoide & $3(4 \%)$ & \\
\hline & Esquizotípico & $0(0 \%)$ & \\
\hline \multirow{4}{*}{ B } & Antisocial & $20(26 \%)$ & \multirow{4}{*}{$35(45 \%)$} \\
\hline & Histriónico & $0(0 \%)$ & \\
\hline & Narcisista & $1(1 \%)$ & \\
\hline & Límite & $14(18 \%)$ & \\
\hline \multirow{3}{*}{ C } & Evitativo & $0(0 \%)$ & \multirow{3}{*}{$2(3 \%)$} \\
\hline & Dependiente & $0(0 \%)$ & \\
\hline & Obsesivo-compulsivo & $2(3 \%)$ & \\
\hline
\end{tabular}

${ }^{53}$ Tabla I. Frecuencia de Cluster y Trastornos de personalidad, tomada de MOHÍNO, Susana, PUJOL, Amadeo e IDIAQUEZ, Itziar, "Personality Disorders and Criminal Responsibility in the Spanish Supreme Court*.", Journal of forensic sciences 56.1 (2011), p. 152. 
AGUSTINA, José y LORENZO, Florencia."Sobre el confuso concepto de psicopatía en la jurisprudencia del Tribunal Supremo español: una revisión crítica ante los nuevos retos del Derecho penal de la peligrosidad".

\begin{tabular}{|l|l|l|l|}
\hline No especificado & & & $16(21 \%)$ \\
\hline Mixto & & & $14(18 \%)$ \\
\hline Total & & & $\mathbf{7 7 ( 1 0 0 \% )}$ \\
\hline
\end{tabular}

La Tabla II, por su parte, recoge la relación de los tipos penales asociados a los distintos trastornos de la personalidad declarados probados en la muestra de sentencias analizadas.

Tabla II: Relación de tipos penales asociados a los TP en las sentencias analizadas. (28 de las 77 sentencias son condenatorias por más de un delito).

\begin{tabular}{|c|c|c|c|c|c|c|}
\hline \multirow[t]{2}{*}{ Subtipo de TP } & \multicolumn{6}{|c|}{ Tipos Penales } \\
\hline & $\begin{array}{l}\text { Asesinato - } \\
\text { Homicidio } \\
\text { N (\%) }\end{array}$ & $\begin{array}{l}\text { Lesiones } \\
\text { N }(\%)\end{array}$ & $\begin{array}{l}\text { Agresiones sexuales } \\
\mathrm{N}(\%)\end{array}$ & $\begin{array}{l}\text { Robos } \\
\text { N (\%) }\end{array}$ & $\begin{array}{l}\text { Contra la } \\
\text { salud pública } \\
\mathrm{N}(\%)\end{array}$ & $\begin{array}{l}\text { Otros } \\
\mathbf{N}(\%)\end{array}$ \\
\hline Paranoide & $4(5)$ & $0(0)$ & $0(0)$ & $2(3)$ & $0(0)$ & $1(1)$ \\
\hline Esquizoide & $1(1)$ & $0(0)$ & $1(1)$ & $0(0)$ & $0(0)$ & $0(0)$ \\
\hline Antisocial & $2(3)$ & $2(3)$ & $1(1)$ & $1(1)$ & $1(1)$ & $2(3)$ \\
\hline Narcisista & $1(1)$ & $0(0)$ & $0(0)$ & $0(0)$ & $0(0)$ & $0(0)$ \\
\hline Límite & $4(5)$ & $1(1)$ & $0(0)$ & $0(0)$ & $2(3)$ & $0(0)$ \\
\hline $\begin{array}{l}\text { Obsesivo- } \\
\text { compulsivo }\end{array}$ & $0(0)$ & $0(0)$ & $1(1)$ & $0(0)$ & $1(1)$ & $0(0)$ \\
\hline Mixto & $14(18)$ & $1(1)$ & $3(4)$ & $1(1)$ & $1(1)$ & $9(12)$ \\
\hline $\begin{array}{l}\text { No } \\
\text { especificado }\end{array}$ & $1(1)$ & $0(0)$ & $1(1)$ & $1(1)$ & $1(1)$ & $2(3)$ \\
\hline $\begin{array}{lr}\text { TP } & + \\
\text { Trastorno } & \text { por } \\
\text { consumo } & \text { de } \\
\text { sustancias } & \text { de } \\
\text { abuso } & \end{array}$ & $\begin{array}{l}14(18)^{1}+ \\
\text { Subtipo } \\
\text { Esquizoide* }\end{array}$ & $7(9)^{2}$ & $5(7)^{3}$ & $\begin{array}{l}14(18) \\
4\end{array}$ & $7(9)^{5}$ & $9(12)^{6}$ \\
\hline TP + CI límite & $0(0)$ & $0(0)$ & $0(0)$ & $3(4)^{7}$ & $0(0)$ & $0(0)$ \\
\hline $\begin{array}{l}\text { TP + trastorno } \\
\text { mental severo }\end{array}$ & $0(0)$ & $0(0)$ & $2(3)^{8}$ & $1(1)^{9}$ & $0(0)$ & $2(1)^{10}$ \\
\hline $\begin{array}{ll}\text { TOTAL } & (127 \\
\text { delitos }) & \end{array}$ & 41 & 11 & 14 & 23 & 13 & 25 \\
\hline
\end{tabular}

* STS 17/07/2008, sobre atentado terrorista (11/03/2004): TP esquizoide asociado a consumo de alcohol y drogas: 191 asesinatos consumados y 1.841 en grado de tentativa. 
Polít. crim. Vol. 11, № 21 (Julio 2016), Art. 4, pp. 66-103.

[http://www.politicacriminal.cl/Vol_11/n_21/Vol11N21A4.pdf]

${ }^{1}$ TP subtipo paranoide 1 caso, TP subtipo antisocial 7 casos, TP subtipo límite 3 casos, TP subtipo no especificado 3 casos.

${ }^{2}$ TP subtipo antisocial 4 casos, TP subtipo límite 1 caso, TP subtipo mixto 2 casos.

${ }^{3}$ TP subtipo límite 3 casos, TP subtipo no especificado 2 casos.

${ }^{4}$ TP subtipo antisocial 4 casos, TP subtipo mixto 2 casos, TP subtipo no especificado 8 casos.

${ }^{5}$ TP subtipo antisocial 2 casos, TP subtipo límite 4 casos, TP subtipo mixto 1 caso.

${ }^{6}$ TP subtipo antisocial 2 casos, TP subtipo límite 2 casos, TP subtipo mixto 1 caso. TP subtipo no especificado 4 casos.

${ }^{7}$ TP subtipo mixto 2 casos, TP subtipo inespecífico 1 caso.

${ }^{8}$ TP subtipo paranoide 2 casos.

${ }^{9}$ TP subtipo antisocial 1 caso.

${ }^{10}$ Por último, TP subtipo antisocial 2 casos.

En la Tabla III se recoge, finalmente, la incidencia en la responsabilidad criminal de los trastornos de personalidad declarados probados en las sentencias analizadas. De la muestra de 77 sentencias, en 19 de ellas (25\%) la incidencia del trastorno diagnosticado es irrelevante a efectos de valorar la imputabilidad. En el resto de las sentencias, sí tiene incidencia en la imputabilidad, atenuando la responsabilidad criminal (atenuante analógica) en $35(45 \%)$ y eximiendo parcialmente de responsabilidad (eximente incompleta) en 23 $(30 \%)$.

Tabla III: Niveles de responsabilidad criminal declarada según subtipos de los TP (con o sin comorbilidad) en las sentencias analizadas

\begin{tabular}{|l|l|l|l|l|}
\hline Subtipo de TP & $\begin{array}{l}\text { Eximente } \\
\mathbf{N}(\%)\end{array}$ & $\begin{array}{l}\text { Eximente } \\
\text { incompleta } \\
\mathbf{N}(\%)\end{array}$ & $\begin{array}{l}\text { Atenuante } \\
\text { analógica } \\
\mathbf{N}(\%)\end{array}$ & $\begin{array}{l}\text { No afectación RC } \\
\mathbf{N}(\%)\end{array}$ \\
\hline Paranoide & $0(0)$ & $3(4)$ & $2(3)$ & $0(0)$ \\
\hline Esquizoide & $0(0)$ & $0(0)$ & $1(1)$ & $1(1)$ \\
\hline Antisocial & $0(0)$ & $0(0)$ & $4(5)$ & $4(5)$ \\
\hline Narcisista & $0(0)$ & $0(0)$ & $0(0)$ & $1(1)$ \\
\hline Limite & $0(0)$ & $0(0)$ & $5(6)$ & $2(3)$ \\
\hline Obsesivo-compulsivo & $0(0)$ & $0(0)$ & $0(0)$ & $2(3)$ \\
\hline Mixto & $0(0)$ & $1(1)$ & $5(6)$ & $4(5)$ \\
\hline No especificado & $0(0)$ & $1(1)$ & $2(3)$ & $3(4)$ \\
\hline $\begin{array}{l}\text { TP + Trastorno por consumo } \\
\text { de sustancias de abuso }\end{array}$ & $0(0)$ & $16(21)$ & $14(18)$ & $2(3)$ \\
\hline TP + CI límite & $0(0)$ & $2(3)$ & $0(0)$ & $0(0)$ \\
\hline TP + trastorno mental severo & & & $2(3)$ & $0(0)$ \\
\hline Total 77 (100) & $0(0)$ & $0(0)$ & $\mathbf{3 5}(\mathbf{4 5})$ & $\mathbf{1 9}(\mathbf{2 5})$ \\
\hline
\end{tabular}

A la vista de los resultados obtenidos, parece conveniente referirse a la incidencia en la responsabilidad criminal en relación a cada uno de los trastornos en particular: 
AGUSTINA, José y LORENZO, Florencia."Sobre el confuso concepto de psicopatía en la jurisprudencia del Tribunal Supremo español: una revisión crítica ante los nuevos retos del Derecho penal de la peligrosidad".

En cuanto al TP paranoide, se declara probado en 7 sentencias (9\%): en $3(4 \%)$ de ellas como eximente incompleta, en $1(1 \%)$ de ellas en comorbilidad con drogas de abuso, y como atenuante analógica en $2(3 \%)$ sentencias. En un 1 de ellas en comorbilidad con trastorno mental severo (síntomas psicóticos y trastorno depresivo recurrente).

El TP esquizoide se declara probado en 3 sentencias (4\%). En 2 (3\%) se aprecia la atenuante analógica, en 1 (1\%) de ellas en comorbilidad con el alcohol, y en otra de las sentencias carece de relevancia.

El TP antisocial se declara probado en 20 de las sentencias analizadas (26\%). Como trastorno especifico en 7 (9\%), y asociado a drogas de abuso en 11 de ellas (14\%). En 1 $(1 \%)$ en comorbilidad con pedofilia y $1(1 \%)$ con esquizofrenia paranoide.

Cabe mencionar que el trastorno específico antisocial en 3 sentencias (4\%) tiene incidencia en la imputabilidad, atenuando la responsabilidad; y en $4(5 \%)$ de las sentencias, no tiene relevancia alguna. También es destacable que cuando el trastorno antisocial se presenta asociado con el consumo de drogas, en $6(8 \%)$ de las sentencias exime parcialmente la responsabilidad, bien apreciando la eximente incompleta de anomalía o alteración física del art. 21.1 del CP, o bien estimando la eximente incompleta de drogadicción del art. 20.2 .Y en $5(6 \%)$ de las sentencias se aprecia la atenuante analógica.

Finalmente se debe apuntar que cuando el trastorno antisocial se presenta asociado con pedofilia o esquizofrenia paranoide (controlada en el momento de los hechos), tiene incidencia en la imputabilidad, apreciando la atenuante analógica de anomalía o alteración psíquica.

En cuanto a los TP de la personalidad narcisista y obsesivo compulsivo declarados probados en tres de las sentencias analizadas: el primero se declara probado en 1 (1\%) y el segundo en 2 (3\%), no teniendo incidencia alguna en ambos casos en la imputabilidad.

En cuanto al TP límite de la personalidad, diagnosticado en 14 (18\%) sentencias, en 5 (6\%) de las sentencias, tiene incidencia en la imputabilidad, apreciando la atenuante analógica de anomalía o alteración psíquica, mientras que en $2(3 \%)$ de las resoluciones no tiene incidencia alguna. Sin embargo, cuando este trastorno se presenta en cormobilidad con drogas de abuso incide en la imputabilidad: en $4(5 \%)$ de las sentencias se exime parcialmente la responsabilidad, en 2 (3\%) se atenúa, apreciando la atenuante analógica y, por último, en 1 de ellas, no tiene relevancia alguna de dicho trastorno.

El TP mixto se declara probado en $14(18 \%)$ sentencias. En $5(6 \%)$ exime parcialmente de responsabilidad por anomalía o alteración psíquica (teniendo incidencia en 3 de ellas, la comorbilidad con el alcohol y drogas, y 1 con CI, respectivamente). En 5 (6\%) de las sentencias se aprecia la atenuante analógica de anomalía o alteración psíquica y en 4 (5\%) no tiene incidencia alguna en la responsabilidad criminal. 
Polít. crim. Vol. 11, № 21 (Julio 2016), Art. 4, pp. 66-103.

[http://www.politicacriminal.cl/Vol_11/n_21/Vol11N21A4.pdf]

El TP no especificado de personalidad se declara probado en $16(21 \%)$ de las sentencias. En $1(1 \%)$ como eximente incompleta de anomalía o alteración psíquica; en 2 (3\%) como atenuante analógica; y en 3 (4\%) sin incidencia alguna en la responsabilidad criminal. Este trastorno se presenta en comorbilidad con drogas de abuso en 9 (12\%) sentencia; 2 (3\%) como eximente incompleta; $6(8 \%)$ como atenuante analógica; y en una de ella es irrelevante. Y por último, en $1(1 \%)$ de las resoluciones se presenta asociado a CI límite, eximiendo parcialmente de la responsabilidad criminal.

Los TP asociados a trastornos por sustancias de abuso se declaran probados en 32 (42\%) de la sentencias analizadas. En $16(21 \%)$ de las resoluciones exime parcialmente de la responsabilidad criminal; en $14(18 \%)$ solo la atenúa; y en $2(3 \%)$ no tiene incidencia alguna en la responsabilidad criminal.

El TP de personalidad asociado a CI límite se declara probado en 2 (3\%) sentencias, con incidencia en la responsabilidad criminal: en una con exención incompleta de responsabilidad criminal y en otra apreciando la atenuante analógica de anomalía o alteración psíquica.

Finalmente, los TP de personalidad asociados a un trastorno severo solo se declaran probados en $2(3 \%)$ sentencias, con incidencia en la imputabilidad, apreciando la atenuante analógica de anomalía o alteración psíquica.

En cuanto a las consecuencias jurídicas del delito (pena y medida de seguridad), hay que poner de relieve que en 58 de las resoluciones (un 75\%) los TP tienen un efecto atenuatorio de la pena. En los supuestos que contemplan una exención incompleta de responsabilidad criminal, la reducción de la pena lo es en un solo grado y nunca en dos (siendo ello facultativo, a criterio del órgano sentenciador, a tenor de lo dispuesto en el art. 68 del Código Penal). Y en los supuestos que aprecian la atenuante analógica de responsabilidad, se impone la pena en su mitad inferior. No teniendo relevancia ninguna en 19 de las sentencias (un $25 \%$ del total).

Por lo que respecta a las medidas de seguridad, es destacable que solo en 4 de las sentencias analizadas hay un pronunciamiento favorable sobre las medidas de seguridad a semiimputables. De las cuatro, solo en 1 de las resoluciones (un 1\%), se impone una medida de internamiento en un centro psiquiátrico al condenado (por un delito de homicidio), diagnosticado de TP paranoide asociado al consumo de sustancias tóxicas, considerándose que tenía disminuidas de forma notable sus capacidades cognitivas y volitivas en el momento de la comisión del delito (STS de 11 de junio de 2009). En las tres resoluciones restantes, el Alto Tribunal remite a la fase de ejecución de sentencia la adopción de una medida de seguridad, dada la peligrosidad del condenado (en dos casos de TP paranoide y en uno de TP no especificado asociado a una grave adicción a sustancias tóxicas ${ }^{54}$.

\footnotetext{
54 Vid., la STS de 11 de junio de 2009, en la que se reconoce la posibilidad de acordar en Sentencia una medida de seguridad, difiriendo su concreción al trámite de ejecución de la sentencia, en incidente contradictorio para determinar la conveniencia de someter al penado a la misma. Señalando el TS, que concurriendo la situación de peligrosidad, la adopción de la medida de seguridad se revela como necesaria y consecuencia de aquélla sin estar sujeta su adopción a petición del Ministerio Fiscal "pues el principio
} 
AGUSTINA, José y LORENZO, Florencia."Sobre el confuso concepto de psicopatía en la jurisprudencia del Tribunal Supremo español: una revisión crítica ante los nuevos retos del Derecho penal de la peligrosidad".

\section{Discusión.}

Nos referiremos en primer lugar a los resultados del estudio descriptivo para, a continuación, realizar algunas valoraciones a partir del mismo y en relación al marco teórico previo.

\subsection{Incidencia del trastorno en la responsabilidad criminal.}

En cuanto a los resultados obtenidos, la muestra de las 77 sentencias analizada revela que el trastorno diagnosticado tuvo incidencia en la responsabilidad criminal en 58 resoluciones (75\%), mientras que en 19 de ellas (25\%) fue irrelevante. Los resultados obtenidos vienen, de este modo, a confirmar lo declarado por la jurisprudencia del Tribunal Supremo de forma reiterada, en relación a que en la doctrina jurisprudencial, la relevancia de los trastornos de la personalidad en la imputabilidad, no responde a una regla general (STS de 22 de octubre de 2003).

La relevancia o irrelevancia del trastorno en la imputabilidad viene motivada en general por la afectación o no a las capacidades cognitivas y/o volitivas en el momento de la comisión del delito y en relación a éste. Pero lo cierto es que la doctrina en esta valoración relativa al juicio de culpabilidad no sigue una línea uniforme. En consecuencia, en las sentencias analizadas nos encontramos tanto con resoluciones en las que se afirma que las "psicopatías no afectan a la capacidad de discernimiento, ni a las facultades de inhibición, autodominio o control" (STS de 28 de junio de 2001); como con algunas en las que se declara, en sentido contrario, que las psicopatías o trastornos de la personalidad afectan "duramente las áreas del conocimiento, del control de los impulsos, o de la afectividad" (STS de 25 de marzo de 2004). Por otra parte, unas sentencias ponen el acento en la vertiente emocional y volitiva, con preservación de la inteligencia (STS de 4 de noviembre de 2002 y STS de 18 de junio de 2001); mientras que en otras se afirma, por el contrario, que "se produce una reducción de las facultades cognitivas" (STS de 7 de mayo de 2001). Si bien es cierto que en las sentencias analizadas el porcentaje mayor de pronunciamientos inciden en las capacidades cognitivas/volitivas, también lo es que en un porcentaje muy elevado se declara la afectación del trastorno solo con respecto a la capacidad volitiva del sujeto, conservando inalterada su capacidad cognitiva.

Asimismo, nos encontramos con resoluciones en las que, pese a declararse la afectación por el trastorno, el mismo no tiene incidencia alguna en la responsabilidad criminal, al no reconocerse su relación con el delito cometido. Cabe referenciar, en este sentido, tres resoluciones en las que, diagnosticados un TP obsesivo compulsivo (STS de 22 de noviembre de 2005), un TP no especificado (STS de 25 de abril de 2005) y, finalmente, un TP límite de la personalidad, asociado este último con trastorno bulímico y dependencia de

acusatorio no puede regir en relación con las medidas de seguridad consecuencia de la peligrosidad del sujeto, como si se tratase de la imposición de una pena, sistema dual que opera en planos distintos”. 
Polít. crim. Vol. 11, № 21 (Julio 2016), Art. 4, pp. 66-103.

[http://www.politicacriminal.cl/Vol_11/n_21/Vol11N21A4.pdf]

drogas (STS de 10 de junio de 2009), los mismos no tuvieron incidencia alguna en la imputabilidad, al no reconocérsele su relación con el delito de tráfico de drogas cometido.

Los resultados revelan asimismo que los trastornos de personalidad más frecuentes en las sentencias analizadas son el TP antisocial (20), el TP no especificado (16), el TP límite y el TP mixto (16). Debiendo señalarse, como dato significativo, que en un porcentaje muy alto se presentan asociados con otros trastornos, en particular con el consumo de sustancias de abuso, siendo estos últimos los de mayor incidencia en la imputabilidad, como veremos infra.

En primer lugar, haremos referencia a los trastornos de personalidad en particular. A este respecto, cabe reseñar que ninguno de ellos dio lugar a la exención completa de la responsabilidad criminal, pero sí a su exención parcial: el TP mixto (1), el TP no especificado (1) y el TP paranoide (3), en tres resoluciones más.

Todos los trastornos, a excepción del TP obsesivo-compulsivo, tuvieron en mayor o menor medida una incidencia atenuatoria en la responsabilidad. Pero debemos señalar que la jurisprudencia, como antes se ha apuntado, ante diagnósticos idénticos no siempre hace el mismo juicio de valor respecto a la imputabilidad. Así se pone de manifiesto en las siguientes resoluciones:

Diagnosticado un TP antisocial al acusado de un delito (robo con intimidación), el Alto Tribunal declara que el referido trastorno no supone modificación alguna de las capacidades de comprender y querer (STS de 3/12/2001) y, en el mismo sentido, en sentencia condenatoria por un delito de asesinato, se declara la inexistencia de alteraciones en sus capacidades intelectiva y volitiva en relación a los hechos imputados (STS de 3/12/09), no teniendo por consiguiente incidencia alguna en la responsabilidad criminal. Mientras que en STS de fecha, 20/01/ 2005 (condenatoria por un delito de lesiones graves), el Alto Tribunal, contempla la atenuante analógica de anomalía o alteración psíquica por afectación leve a sus capacidades de entender y querer, imponiendo la pena en su grado mínimo.

Lo mismo puede decirse para otros trastornos. Diagnosticado un TP mixto (disocial/paranoide) al acusado por una pluralidad de delitos (homicidio, asesinato, detención ilegal, etc.), se declara que el referido trastorno no incidió en la conducta criminal y, por consiguiente, no fue valorado (STS de 16 de octubre de 2000). Mientras que en STS de fecha 9 de julio de 2001, diagnosticado el referido trastorno al acusado por tres delitos de agresión sexual, se declara que el mismo perturbaba parcialmente sus capacidades volitivas, apreciándole la eximente incompleta de anomalía psíquica del art. 21.1 del CP en relación con el art. 20.1 del mismo cuerpo legal.

En el mismo sentido se encuentra la STS de 3 de octubre de 2002: diagnosticado un TP límite al acusado (de un delito de homicidio), el Alto Tribunal declaró la no afectación del mismo a las capacidades de comprender y actuación, no siendo valorado en sede de imputabilidad. Mientras que en la STS de 16 de febrero de 2004, probado el referido trastorno, se declara que el acusado (de un delito de homicidio en grado de tentativa), no 
AGUSTINA, José y LORENZO, Florencia."Sobre el confuso concepto de psicopatía en la jurisprudencia del Tribunal Supremo español: una revisión crítica ante los nuevos retos del Derecho penal de la peligrosidad".

podía actuar conforme a la comprensión de la ilicitud del hecho delictivo, apreciándosele la atenuante analógica.

A continuación, pasamos a analizar los resultados obtenidos en relación a la incidencia de los TP en la imputabilidad cuando se presentan en comorbilidad con otros trastornos o con el consumo de drogas de abuso ${ }^{55}$.

En primer lugar hay que puntualizar, en cuanto a la incidencia de las toxicomanías en el psicópata, que por la doctrina jurisprudencial se viene afirmando que puede llevar a la aplicación de la eximente incompleta o atenuante analógica. Pero lo cierto es que no siempre es así, como veremos en algunas de las resoluciones analizadas.

A modo de ilustración, diagnosticado un TP antisocial asociado con consumo de drogas de abuso, en unas sentencias el Alto Tribunal aprecia la eximente incompleta de anomalía o alteración psíquica del art. 21.1 en relación al art. 20.1 del CP, por afectación del trastorno a la imputabilidad en relación a los hechos, bien por merma considerables de sus capacidades intelectiva y volitiva (STS 10 de marzo de 2009), o bien por su relevancia funcional en el delito (contra la salud pública), por severa disminución de sus frenos inhibitorios (en actos referidos o que tiendan a la posesión de drogas para su consumo) (STS de 30 de abril de 1999). Sin embargo, en otras resoluciones no contempla la incidencia del trastorno en la imputabilidad (delito de robo con intimidación), y sí la politoxicomanía de larga duración por afectar al control de los impulsos (capacidad volitiva) (STS 20 de febrero de 1998), aplicándose la eximente incompleta de drogadicción del art. $21.2^{\circ}$ del CP.

\footnotetext{
55 La Organización Mundial de la Salud (OMS) define la comorbilidad o diagnóstico dual como la coexistencia en el mismo individuo de un trastorno inducido por el consumo de una sustancia psicoactiva y de un trastorno psiquiátrico (OMS, 1995). Sobre la etiología vid., LUIS TORRES LARRAÑAGA, José, "Comorbilidad de trastornos mentales y adicciones", Revista Liber Adicctus, 2006. Los estudios actuales sobre las relaciones causales entre los trastornos psiquiátricos y los inducidos por sustancias no son concluyentes. Los síntomas de los trastornos mentales y de los problemas de adicción interactúan y se condicionan mutuamente. Las pruebas obtenidas indican que los trastornos psiquiátricos suelen presentarse antes que los trastornos inducidos por el consumo de sustancias, es decir, aumentan la susceptibilidad del individuo frente a estos problemas. Sin embargo, los trastornos psiquiátricos también pueden verse agravados por el consumo de drogas. Sobre comorbilidad en los trastornos de la personalidad, vid. UTGÉS NOGUÉS, Maite, Los Trastornos de personalidad en adictos a la heroína y la seroconversión al VIH, una asociación relevante, Tesis Doctoral, Barcelona: Universidad Autónoma de Barcelona, Facultad de Medicina, 2005, referenciando los estudios sobre las relaciones entre los distintos tipos de trastornos y las hipótesis de investigación en patología dual. En el área específica de las conductas adictivas, el término "patología dual”, se utiliza generalmente para referirse a la coexistencia de trastornos psicopatológicos de los Ejes I y II, concomitante con trastornos por consumo de sustancias. La comorbilidad entre trastorno de personalidad y abuso de sustancias, es objeto de un amplio debate sobre que trastorno aparece con anterioridad si el de la personalidad previa o si el trastorno de la personalidad aparece como consecuencia del uso y abuso de sustancias.
} 
Polít. crim. Vol. 11, № 21 (Julio 2016), Art. 4, pp. 66-103.

[http://www.politicacriminal.cl/Vol_11/n_21/Vol11N21A4.pdf]

Finalmente, en otras ocasiones el Alto Tribunal aprecia la atenuante analógica de anomalía o alteración psíquica, valorando la incidencia del trastorno en la imputabilidad por comportamiento desinhibido, desprecio de normas prohibitivas, sin recabar en la ilicitud de los medios (STS de 16 de octubre de 2000), o por tener disminuida su capacidad de reflexión intelectiva y volitiva (STS 23/05/2005), imponiendo la pena en su mitad inferior.

Por lo que hace referencia a las sentencias en las que se declara probado el TP límite asociado con el consumo de drogas de abuso, la jurisprudencia tampoco mantiene una línea uniforme, de modo similar a como hemos apuntado para otros trastornos. Nos encontramos, pues, con sentencias en las que se aprecia la eximente incompleta de anomalía o alteración psíquica por grave afectación de las capacidades cognitivas y volitivas (STS de 28 de diciembre de 2000), mientras que en otras resoluciones se aprecia una doble valoración de la incidencia en la imputabilidad, contemplándose además de la eximente incompleta de anomalía y alteración psíquica del art. 21.1 en relación al art. 20.1 del CP, la eximente de intoxicación del art. 21.2 del CP (STS 19 de octubre de 2001). Hay que señalar que la comorbilidad en el sujeto afectado por el trastorno de personalidad y la intoxicación, también es objeto de doble valoración por la Jurisprudencia, cuando esta incidencia en la imputabilidad es leve, apreciando además de la atenuante analógica de anomalía o alteración psíquica, la de intoxicación (STS de 4 de diciembre de 2001).

Cabe señalar que en dos de las sentencias analizadas la comorbilidad del TP con el consumo de drogas de abuso no tuvo incidencia alguna en la responsabilidad criminal. Así, diagnosticado un TP límite asociado con trastorno bulímico y dependencia de cocaína, no fue objeto de valoración alguna en la imputabilidad, por no afectación reconocida en relación al delito (tráfico de drogas) (STS de 10 de junio de 2009). En el mismo sentido, diagnosticado un TP no especificado con drogadicción, tampoco tuvo incidencia alguna, por tener el acusado (delito de homicidio en grado de tentativa) conservadas sus facultades cognitivas y volitivas (STS de 25 de marzo de 2004). Por consiguiente, los trastornos de personalidad en comorbilidad con consumo de drogas de abuso no siempre tienen relevancia en el juicio de culpabilidad.

Para finalizar, debemos hacer referencia a los trastornos de personalidad cuando se presentan asociados con CI límite o con un trastorno mental severo. Como es sabido, es doctrina general que solo en supuestos especialmente graves, generalmente asociados a otras patologías, han sido valorados como eximentes incompletas (STS de 22 de octubre 2003). Pues bien, de las sentencias analizadas solo hemos hallado (4) resoluciones con estos diagnósticos. Una de ellas con TP mixto (STS de 5 de junio de 1998) y otra con TP no especificado (STS de 9 de febrero de 2001), asociados a CI límite, apreciándose en ambas la eximente incompleta de anomalía o alteración psíquica. Y en dos resoluciones más: una con diagnóstico TP paranoide asociado con síntomas psicóticos y trastorno depresivo recurrente, con incidencia en la imputabilidad, por disminución no importante de la capacidad de autodeterminación (STS de 19 de enero de 2000) y otra con diagnostico TP antisocial asociado a esquizofrenia paranoide (controlada), con incidencia en la imputabilidad, por afectación leve a las capacidades cognitivas y volitivas (STS de 29 de mayo de 2003), contemplando el Alto Tribunal la atenuante analógica de anomalía o alteración psíquica. 
AGUSTINA, José y LORENZO, Florencia."Sobre el confuso concepto de psicopatía en la jurisprudencia del Tribunal Supremo español: una revisión crítica ante los nuevos retos del Derecho penal de la peligrosidad".

5.2. Nos disponemos ahora a realizar algunas valoraciones a partir del estudio realizado y en relación al marco teórico previo. Conviene subrayar, en todo caso, que pretendemos tan solo apuntar de forma (muy) limitada algunas reflexiones sobre una cuestión de enorme calado.

En efecto, como ha señalado la doctrina, mediante la LO 5/2010 y la introducción de la nueva medida de libertad vigilada a imputables peligrosos se han empezado a sentar las bases de una nueva configuración del sistema punitivo español, abierto desde esa fecha a la yuxtaposición de penas y medidas ${ }^{56}$. Teniendo en cuenta que, entre los sujetos imputables peligrosos, se encuentran aquellos con personalidades psicopáticas, resulta innecesario ahondar en la conveniencia de profundizar en la importancia de una clarificación del diagnóstico clínico y de su correlativo constructo jurídico para afrontar con ciertas garantías los retos de un nuevo Derecho penal de la peligrosidad.

Más allá del alcance y aplicación concretas de esta nueva medida ${ }^{57}$, la doctrina ha visto en su introducción un paso más en la línea de poner en tela de juicio el modelo de la doble vía y, sobre todo, ha agudizado el debate sobre la legitimidad de las medidas de seguridad, en la medida en que éstas nacen y se desarrollan al margen de las garantías del Derecho penal. El hecho de que las medidas puedan imponerse sin que concurra culpabilidad en el sujeto o, en su caso, por encima de la medida de su culpabilidad, requiere lógicamente de una justificación particular. En síntesis, se podría afirmar que cuando la seguridad comunitaria lo exige de modo ineludible sería asumible (y, por tanto, legítimo) que a un ciudadano que se le imponga la medida que, con independencia de su culpabilidad, resulte necesaria ${ }^{58}$. Como ha señalado Silva Sánchez, debería redistribuirse el riesgo generado por este tipo de sujetos y que el mismo no sea sufrido solo por la sociedad, considerando apropiado, por

\footnotetext{
${ }^{56}$ Vid. sobre el particular, en extenso, GARCÍA RIVAS, Nicolás, "La libertad vigilada y el Derecho penal de la peligrosidad”, en: DEMETRIO CRESPO, Eduardo (Dir.), MAROTO CALATAYUD, Manuel (Coord.), Neurociencias y Derecho penal. Nuevas perspectivas en el ámbito de la culpabilidad y tratamiento jurídicopenal de la peligrosidad. Buenos Aires-Montevideo-Madrid: BdeF y Edisofer, 2013, pp. 601 y ss.

57 Para un amplio estudio de la medida de seguridad de libertad vigilada, vid., al respecto, GARCIA ALBERO, Ramón, "La nueva medida de seguridad de libertad vigilada", Revista Aranzadi Doctrinal, núm. 6 (2010), quien considera que la oportunidad de la medida de libertad vigilada postpenitenciaria para autores imputables peligrosos se revela sin necesidad de apelar a un argumento de emulación a la regulación en otros países, dada la existencia de determinados sujetos que precisan de una fase intermedia entre el cumplimiento en régimen ordinario de prisión y la libertad definitiva (p. 2). Analiza este autor la naturaleza y contenido de la medida, señalándose que las obligaciones y prohibiciones que la dotan de contenido constituyen un catálogo cerrado, pretendiendo unas medidas un control genérico o especifico del penado y otras, simplemente, proteger a la víctima. Respecto a la obligación de sometimiento a tratamiento externo o de sometimiento a control médico periódico, plantea la necesidad su consentimiento previo en los penados imputables. Y añade que el diferimiento en la concreción de su contenido concreto de libertad vigilada impuesta en sentencia, y la posibilidad del Juez de dejar sin efecto la misma (en función de si en el momento de su aplicación, las necesidades de control a la vista del pronóstico de reinserción social subsisten o no), convierten la medida de seguridad impuesta en sentencia en una medida sometida a condición resolutoria.

${ }^{58}$ Aborda la cuestión GARCÍA RIVAS, "La libertad vigilada y el Derecho penal de la peligrosidad", cit. nota $\mathrm{n}^{\circ}$ 56, pp. 610 y ss., señalando que esta delicada intervención del Estado se legitima en una ponderación de bienes e intereses de modo similar a como se opera en el estado de necesidad justificante.
} 
Polít. crim. Vol. 11, № 21 (Julio 2016), Art. 4, pp. 66-103.

[http://www.politicacriminal.cl/Vol_11/n_21/Vol11N21A4.pdf]

tanto, en estos casos la previsión de medidas de seguridad privativas de libertad que complementen la pena ${ }^{59}$. La idea básica, pues, que ha obtenido respaldo de un sector de nuestra doctrina es que "existe Derecho penal" más allá de los estrechos límites del Derecho penal de la culpabilidad, enriquecida ésta por la posibilidad de que en el ámbito del Derecho penal de la peligrosidad es posible sumar medidas a penas ${ }^{60}$.

En efecto, la introducción de la medida de libertad vigilada responde a una decisión político-criminal dirigida a incrementar la seguridad de los ciudadanos ante la excarcelación de sujetos culpables de cometer graves delitos y cuya estancia en prisión, cumpliendo penas de larga duración, no ha logrado erradicar su peligrosidad. Esta decisión afecta a nuestro ordenamiento punitivo (penas para los imputables y medidas de seguridad para los inimputables o semi-imputables) al posibilitar su imposición no en sustitución de la pena, como en los sujetos inimputables, sino además de la pena y para su cumplimiento sucesivo: así se establece en el art. 106.2 del Código Penal, suponiendo una extensión del Derecho penal de la peligrosidad.

Desde el punto de vista criminológico, la finalidad principal y prioritaria que se sigue con dicha medida, a tenor de las medidas y obligaciones que la dotan de contenido, es la reinserción del sujeto a la sociedad, y por ende el carácter correctivo que debe informar su ejecución, así como responder a consideraciones asegurativas (obligación de estar siempre localizable, obligación de presentarse periódicamente en el lugar que el Juez o Tribunal establezca etc.). Con todo, está por verse la eficacia de la misma.

Pues bien, sentado lo anterior, a la vista del análisis crítico del estudio realizado salta a la vista que resulta más necesaria que nunca una mejora sustancial de los instrumentos técnicos y jurídicos en relación con la psicopatía y otros trastornos de la personalidad. Y ello no solo para determinar la incidencia de un posible trastorno en la imputabilidad del sujeto, sino también a efectos de valorar su peligrosidad. A este respecto, en relación a los dos métodos posibles que la doctrina especializada distingue para evaluar la peligrosidad de un sujeto (el psicológico-clínico y el estadístico) ${ }^{61}$, es obvio que el método estadístico o actuarial -basado, como es sabido, en la confección de un elenco de indicios que acompañan a los delincuentes reincidentes- sería de aplicación solo en relación al pronóstico de peligrosidad. Con todo, ambos métodos han sido objeto de crítica porque, en

\footnotetext{
${ }^{59}$ SILVA SÁNCHEZ, "El contexto del anteproyecto de reforma del Código Penal de 2008", cit. nota n 48.

${ }^{60}$ GARCÍA RIVAS, "La libertad vigilada y el Derecho penal de la peligrosidad", cit. nota ${ }^{\circ}$ 56, p. 614; CEREZO MIR, "Reflexiones críticas sobre algunas manifestaciones", cit. nota $n^{\circ} 47$; ZUGALDÍA ESPINAR, José Miguel, "Medidas de seguridad complementarias y acumulativas para autores peligrosos tras el cumplimiento de la pena", Revista de Derecho Penal y Criminología, 2009-1; GRACIA MARTíN, Luis, "Sobre la legitimidad de las medidas de seguridad contra delincuentes imputables peligrosos en el Estado de Derecho", Estudios Penales en homenaje a Enrique Gimbernat, t. I, Madrid, 2008; FEIJOO SÁNCHEZ, Bernardo, "Derecho penal y neurociencias, ¿una relación tormentosa?", InDret 3/2007; SÁNCHEZ LÁZARO, F.G., "Deconstruyendo las medidas de seguridad", InDret 2/2010; ROBLES PLANAS, Ricardo, "Sexual predators. Estrategias y límites del Derecho penal de la peligrosidad", InDret núm.4/2007; BALDOVA PASAMAR, Miguel Ángel, "Consideraciones político-criminales sobre la introducción de la pena de libertad vigilada", en: VV.AA., El anteproyecto de modificación del Código Penal de 2008. Algunos aspectos, Cuadernos Penales José María Lidón, núm. 6, Bilbao: Deusto Publicaciones, 2009.

${ }^{61}$ Vid. GARCÍA RIVAS, "La libertad vigilada y el Derecho penal de la peligrosidad", cit. nota n ${ }^{\circ} 56$, pp. 614615.
} 
AGUSTINA, José y LORENZO, Florencia."Sobre el confuso concepto de psicopatía en la jurisprudencia del Tribunal Supremo español: una revisión crítica ante los nuevos retos del Derecho penal de la peligrosidad".

definitiva, ambos solo pueden aportar un juicio de pronóstico basado en meras probabilidades, que no se estructuran en datos científicos infalibles.

Y es que más allá del fundamento y de la legitimidad de las consecuencias jurídicas aplicables, el problema práctico verdaderamente difícil de resolver se refiere a la base probatoria sobre la que, una vez verificado el sustento clínico en relación con el trastorno de la personalidad, se adopta una determinada decisión por parte del órgano sentenciador o, en su caso, del Juez de Vigilancia Penitenciaria.

En éste, como en otros ámbitos, sería deseable llegar a una suerte de "métrica jurídica" que acercara la realidad empírica del riesgo al ámbito de la toma de decisiones valorativas por parte de los órganos jurisdiccionales. Lee Loevinger acuñó, en este sentido, el término "jurimetrics" con la finalidad de subrayar la importancia del método científico y, por tanto, de los métodos estadísticos en la labor de los juristas. Previendo numerosas aplicaciones prácticas de la aplicación de métodos estadísticos al Derecho, Loevinger sostuvo que el conocimiento acerca de la Ley podía obtenerse mediante la observación, más que a través de la especulación. Franken definió jurimetrics como "la aplicación de métodos cuantitativos a los problemas legales”. Y De Mulder et al. precisaron la definición de esta nueva aproximación a los problemas de aplicación práctica del Derecho mediante tres notas características: (i) el estudio empírico de los fenómenos jurídicos; (ii) con la ayuda de modelos matemáticos; (iii) sobre la base de un individualismo metodológico $(=\text { racionalidad })^{62}$.

El camino va a ser tortuoso y difícil de recorrer, pero el necesario entendimiento del mundo jurídico y del mundo médico-forense en esta materia es inaplazable si, como parece, nos adentramos en un Derecho penal de la peligrosidad (o de la seguridad).

\section{Conclusiones.}

1.- El análisis de la muestra de sentencias del Tribunal Supremo examinadas ha puesto de manifiesto la confusión en la utilización de una terminología sui generis que, en ocasiones, viene empleando el Alto Tribunal al referirse a la psicopatía. En efecto, se han identificado distintas expresiones como "trastorno psicopático" (STS 20/12/2005), "trastorno de personalidad (psicopatía)" (STS 28/04/2000), "trastorno de la personalidad de naturaleza psicopática"(STS 3/04/2001), STS 14/10/2002), "trastorno de personalidad tipo limite, emocionalmente inestable (psicopatía)" (STS 19/10/2001), "trastorno de la personalidad o psicopatía" (STS de 2 de enero 2004), "psicopatía o trastorno del comportamiento crónica de escasa entidad" (STS 19/07/2004), "trastorno disocial límite" (STS 13/12/05), o "trastorno de la personalidad antisocial con rasgos psicopáticos" (STS 25/01/2006). Ello dificulta, sin duda, su valoración y aplicación por parte de los Jueces y Tribunales, por lo

\footnotetext{
${ }^{62}$ Para las citas de autores y sobre esta cuestión en general vid. a este respecto, AGUSTINA, José R. y MARTINEZ JARIOD, Adela, "La aplicación judicial de la medida de prisión provisional: un enfoque criminológico", Cuadernos de Política Criminal, Número 107, II, Época II, octubre 2012, pp. 278 y ss.
} 
Polít. crim. Vol. 11, № 21 (Julio 2016), Art. 4, pp. 66-103.

[http://www.politicacriminal.cl/Vol_11/n_21/Vol11N21A4.pdf]

que sería conveniente que las clasificaciones internacionales de las enfermedades mentales (DSM-V y CIE 10) fueran expresamente utilizadas por los Tribunales de Justicia y exigidas en sus dictámenes a los peritos médicos.

2.- La doctrina jurisprudencial, al valorar la incidencia de los trastornos de la personalidad (TP) y psicopatía en la imputabilidad, no responde a una regla general. Nos encontramos, pues, con idénticos diagnósticos declarados probados en sentencia, que la jurisprudencia considera con distinta relevancia: (i) en unas ocasiones, no tienen incidencia alguna en las capacidades cognitivas y/o volitivas del sujeto en relación con el delito cometido; (ii) en otras, considera que tienen una incidencia grave o leve, y aprecia la eximente incompleta o atenuante analógica de anomalía o alteración psíquica, debiendo estarse al caso concreto, en atención a la intensidad del trastorno y su relación con el delito cometido; (iii) en todo caso, no se ha hallado ningún supuesto en que la incidencia del referido trastorno en la imputabilidad eximiera completamente de responsabilidad criminal.

3.- A la luz de los resultados obtenidos, los trastornos de personalidad que más incidencia tienen en la imputabilidad son el paranoide, límite, no especificado y el antisocial, pero sin llegar eximir totalmente la responsabilidad criminal.

4.- Generalmente, en los supuestos más frecuentes de comorbilidad (TP asociado a drogas de abuso), se aprecia una mayor la incidencia del diagnóstico en la imputabilidad, eximente incompleta o atenuante analógica de anomalía o alteración psíquica. Sin embargo, hay que puntualizar que, en el algunos casos, TP diagnosticado no tiene incidencia alguna en la imputabilidad y sí la drogodependencia de larga duración o el consumo de drogas de abuso o alcohol, apreciándose por tal motivo una eximente incompleta por drogadicción o intoxicación (referida al art. 20.2 del Código Penal). Por el contrario, en otras resoluciones tanto el TP como la drogadicción son objeto de doble valoración en el juicio de culpabilidad, apreciándose una eximente incompleta de anomalía o alteración psíquica (referida al art. 20.1 CP) y otra eximente de intoxicación (referida al art. 20.2 CP).

5.- En la condena por delitos cometidos por sujetos afectados por la denominada jurisprudencialmente psicopatía o TP (considerados por la jurisprudencia imputables o semi-imputables), el reconocimiento de dichos trastornos solo tiene una incidencia relativa en la pena, imponiéndose ésta en su mitad inferior o, a lo sumo, rebajándose a la pena inferior en un solo grado.

6.- La adopción de medidas de seguridad para los semi-imputables por la denominada jurisprudencialmente psicopatía o TP es excepcional.

7.- Se ha podido constatar una relación entre la concurrencia de los TP con la comisión de delitos violentos (asesinatos, homicidios, lesiones graves, robos con intimidación y otros como salud pública) y la condena por múltiples delitos.

8.- Todo lo anteriormente analizado subraya la necesidad de dotar al sistema penal de medidas de seguridad efectivas y de programas específicos de intervención a fin de evitar la reiteración delictiva de los delincuentes psicópatas peligrosos. 
AGUSTINA, José y LORENZO, Florencia."Sobre el confuso concepto de psicopatía en la jurisprudencia del Tribunal Supremo español: una revisión crítica ante los nuevos retos del Derecho penal de la peligrosidad".

9.- En cuanto a la reciente implementación de la medida de seguridad de libertad vigilada para sujetos imputables (aplicable solo en los casos expresamente previstos en el Código Penal), imponiéndose ésta de forma acumulada y con posterioridad a la pena de prisión impuesta en Sentencia, consideramos que es positiva -pese a las críticas de parte de la doctrina- y puede servir para dar respuesta a la peligrosidad subsistente tras el cumplimiento de la pena privativa de libertad en determinados sujetos, como en el caso de los psicópatas.

10.- A este respecto, puede llegar a afirmarse que determinados sujetos precisan de una fase intermedia entre el cumplimiento en régimen ordinario de prisión y la libertad definitiva. Y como quiera que la libertad condicional es difícil de asumir para ciertos delincuentes peligrosos, la libertad vigilada impuesta a imputables vendría a ser, materialmente y demorada en el tiempo, lo que en buena técnica procesal debería haber sido también para delincuentes con mal pronóstico la libertad condicional previa a la excarcelación ${ }^{63}$.

11.- La relevancia práctica del estudio clínico y forense de la psicopatía y los trastornos de la personalidad se ha acentuado en los últimos años, en los que, asimismo, se ha generado un creciente interés por el estudio de la imputabilidad penal desde las neurociencias y su impacto en el Derecho penal. Sobre la base de los nuevos descubrimientos, se ha empezado a apuntar que, al menos en algunos casos, la psicopatía podría eliminar la imputabilidad en un futuro no demasiado lejano.

12.- Todo ello conduce a que sea más necesaria todavía una utilización rigurosa de las categorías médico-forenses por parte de los Jueces y Tribunales: ante un mayor conocimiento científico de la psicopatía en general y los avances técnicos para predecir su peligrosidad en un sujeto concreto, será determinante que la jurisprudencia opere con criterios predecibles. Y ese objetivo solo se puede lograr, de entrada, con un lenguaje claro, coherente y lo más preciso posible, tanto por lo que se refiere al fundamento de una eximente de responsabilidad criminal (imputabilidad), como por lo que afecta al sustento del pronóstico de peligrosidad que justificaría una medida de libertad vigilada posterior a la ejecución de la pena. En este último aspecto se abren nuevos retos para el Derecho penal de la peligrosidad que requerirán mucha mayor atención por los operadores jurídicos, a riesgo de que el sistema funcione con parámetros inestables en cuanto al principio de seguridad jurídica.

13.- La (limitada) discusión que se ha efectuado en torno a la legitimidad o fundamento de las medidas de seguridad y a las condiciones para la imposición de las mismas ha puesto en evidencia que nos adentramos ante un reto todavía mayor a la vista de la evolución que se constata en la valoración de la psicopatía y los trastornos de la personalidad desde el punto

${ }^{63}$ GARCIA ALBERO, Ramón, "La nueva medida de seguridad de libertad vigilada", Revista Aranzadi Doctrinal núm. 6/2010. 
Polít. crim. Vol. 11, № 21 (Julio 2016), Art. 4, pp. 66-103.

[http://www.politicacriminal.cl/Vol_11/n_21/Vol11N21A4.pdf]

de vista clínico y jurisprudencial. A este respecto, es obvio que el problema de legitimidad no se limita solo a casos asociados al tratamiento de casos de imputables peligrosos. A modo de ejemplo, se deberían repensar los motivos que llevan a justificar que la falta de relación de la patología evidenciada con el delito cometido se traduzca en que, en de conformidad con una corriente doctrinal y jurisprudencial bastante consolidada, se deba descartar la aplicación de medidas de seguridad. 
AGUSTINA, José y LORENZO, Florencia."Sobre el confuso concepto de psicopatía en la jurisprudencia del Tribunal Supremo español: una revisión crítica ante los nuevos retos del Derecho penal de la peligrosidad".

\section{REFERENCIAS}

AGUSTINA, José R. y MARTÍNEZ JARIOD, Adela, "La aplicación judicial de la medida de prisión provisional: un enfoque criminológico", Cuadernos de Política Criminal, Número 107, II, Época II, octubre 2012.

BALDOVA PASAMAR, Miguel Ángel, "Consideraciones político-criminales sobre la introducción de la pena de libertad vigilada", en: VV.AA., El anteproyecto de modificación del Código Penal de 2008. Algunos aspectos, Cuadernos Penales José María Lidón, núm. 6, Bilbao: Deusto Publicaciones, 2009.

BELLOCH FUSTER, A., SANDIN, B. y RAMOS, F., Manual de psicopatología, Madrid: McGraw-Hill, DL, 2002.

CANCIO MELIÀ, Manuel, Psicopatía y Derecho Penal: algunas consideraciones introductorias, en: DEMETRIO CRESPO, Eduardo (Dir.), MAROTO CALATAYUD, Manuel (Coord.), Neurociencias y Derecho penal. Nuevas perspectivas en el ámbito de la culpabilidad y tratamiento jurídico-penal de la peligrosidad. Buenos Aires-Montevideo-Madrid: BdeF y Edisofer, 2013.

CANO LOZANO, M.C., "Trastornos psicopatológicos relacionados con la imputabilidad" en: SIERRA, J.C., JIMÉNEZ, E.Ma . y BUELA-CASAL G. (Coords.), Psicología forense: Manual de técnicas y aplicaciones, $2^{\mathrm{a}}$ ed., Madrid: Biblioteca Nueva, 2010.

CARRASCO GÓMEZ, J.J., Trastornos de la Personalidad. Concepto. Clasificación de la OMS (I.C.D.X) y consideraciones médico forenses. Cuadernos de Derecho Judicial. Medicina Legal, núm. V, Ed. Consejo General del Poder Judicial, Madrid, 1993.

CEREZO MIR, J., Curso de Derecho Penal español. Parte General, III. Teoría Jurídica del delito/2, $1^{\mathrm{a}}$ ed. Madrid: Técnos, 2005.

, "Reflexiones críticas sobre algunas manifestaciones de la moderna tendencia a incrementar el rigor en la exigencia de responsabilidad criminal”, Ed. Revista Penal núm.22 (2008).

CLECKLEY, H.M., The Mask of Sanity, 5 ed. ST Louis, MO: Mosby, 1976.

CUELLO CONTRERAS, J., El Derecho Penal Español. Parte General. Nociones Introductorias. Teoría del delito. $3^{\mathrm{a}} \mathrm{ed}$, Madrid: ed. Dikynson, 2002.

FEIJOO SÁNCHEZ, B., "Derecho penal y neurociencias, ¿una relación tormentosa?", InDret 3/2007.

FOMBELLIDA VELASCO, L., "Valoración Médico-legal de los trastornos de la personalidad. Estudio Jurisprudencial", Revista del Consejo general del Poder Judicial. Estudio Jurisprudencial no 40 (1995).

GARCÍA ALBERO, R., "La nueva medida de seguridad de libertad vigilada", Revista Aranzadi Doctrinal n' 6 (2010).

GARCÍA RIVAS, Nicolás, "La libertad vigilada y el Derecho penal de la peligrosidad", en: DEMETRIO CRESPO, Eduardo (Dir.), MAROTO CALATAYUD, Manuel (Coord.), Neurociencias y Derecho penal. Nuevas perspectivas en el ámbito de la culpabilidad y tratamiento jurídico-penal de la peligrosidad. Buenos Aires-Montevideo-Madrid: BdeF y Edisofer, 2013. 
Polít. crim. Vol. 11, № 21 (Julio 2016), Art. 4, pp. 66-103.

[http://www.politicacriminal.cl/Vol_11/n_21/Vol11N21A4.pdf]

GARRIDO GENOVÉS, V., El psicópata: un camaleón en la sociedad actual, $7^{\mathrm{a}}$ ed., Valencia: Algar, 2005.

GRACIA MARTÍN, L., "Sobre la legitimidad de las medidas de seguridad contra delincuentes imputables peligrosos en el Estado de Derecho", en: VV.AA., Estudios Penales en homenaje a Enrique Gimbernat, t. I, Madrid: Edisofer, 2008.

HARE, R.D., La naturaleza del psicópata: algunas observaciones para entender la violencia depredadora humana, en: RAINE, A., y SAN MARTÍN, J. (Eds.), "Violencia y psicopatía", 2a ed., Barcelona: Ariel, 2002.

JIMÉNEZ DIEZ, M.J. y FONSECA MORALES, G.M., Trastornos de las personalidades (psicopatías), Madrid: CESEJ- Ediciones, 2007.

LEAL MEDINA J., "La psicopatía y su incidencia como anomalía psíquica en la doctrina del Tribunal Supremo. La interacción de los factores biológicos, genéticos y ambientales en el juicio de imputabilidad", Revista de Derecho y Proceso Penal $\mathrm{n}^{\circ} 10$ (2003/2), Navarra: Thomson-Aranzadi, 2003, p.173.

LÓPEZ MIGUEL María José y NÚÑEZ GAITÁN, María del Carmen, "Psicopatía versus trastorno antisocial de la personalidad", Revista Española de Investigación Criminológica.Articulo1, Número 7 (2009).

MAZA MARTÍN J.M., "Las medidas de seguridad y otras opciones penales aplicables a los supuestos de inimputabilidad plena y semiplena. Problemática judicial.”, Cuadernos de derecho Judicial, $\mathrm{N}^{\circ} 7$ (1993).

MILLON, T., DAVIS, R.D. et al., Trastornos de la personalidad: más allá del DSM-IV (1 ${ }^{\mathrm{a}}$ ed., reimpr.), Barcelona: Masson, 2004.

MIR PUIG, Santiago, Derecho Penal Parte General, 6ª ed., Madrid: Ed. Reppertor, 2002.

MOHÍNO, Susana, PUJOL, Amadeo e IDIAQUEZ, Itziar, "Personality Disorders and Criminal Responsibility in the Spanish Supreme Court*", Journal of forensic sciences 56.1 (2011).

ORTEGA MONASTERIO, Leopoldo, "Semiológica y aspectos médicos-legales de los grandes síndromes psicológicos”, en: ORTEGA MONASTERIO et. al., Sicopatología Jurídica y Forense, Barcelona: PPU, 1991.

ORTEGA MONASTERIO, Leopoldo, GÓMEZ-DURÁN, E.L., "Psiquiatría Jurídica y Forense”, en: VALLEJO RUILOBA J. (Ed.), Introducción a la psicopatología y la psiquiatría. Barcelona: Elsevier, 2011.

PICHOT, P., "Psychopathic behaviour: a historical overview", en: HARE R.D., SCHALLING D. (Eds.), Psychopathic behaviour: Approaches to research, Chichester: John Wiley \& Sons (1978).

PINEL, P., Traité médico-philosophique sur laliénation mentale, $2^{\mathrm{a}}$ ed., Paris: Brosson (1809).

PRICHARD, J.C., A treatise on insanity and other disorders affecting the mind. London: Sherwood, Gilbert and Piper, 1835..

ROBLES PLANAS, Ricardo, "Sexual predators. Estrategias y límites del Derecho penal de la peligrosidad", InDret 4/2007.

RUBIO LARROSA, Vicente, Los trastornos de la personalidad. Sus tipos, (disponible en Internet: http://usuarios.discapnet.es/border/tlprubio.htm).

SÁNCHEZ GARRIDO, Francisco, "El tratamiento jurisprudencial de la psicopatía",

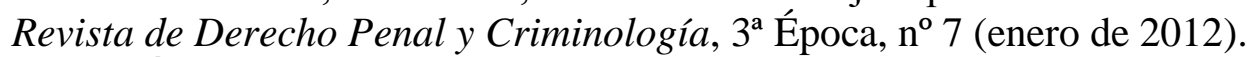

SÁNCHEZ LÁZARO, F.G., "Deconstruyendo las medidas de seguridad", InDret 2/2010. 
AGUSTINA, José y LORENZO, Florencia."Sobre el confuso concepto de psicopatía en la jurisprudencia del Tribunal Supremo español: una revisión crítica ante los nuevos retos del Derecho penal de la peligrosidad".

SILVA SÁNCHEZ, Jesús-María, "El contexto del anteproyecto de reforma del Código Penal de 2008”, en: VV. AA., El Anteproyecto de modificación del Código Penal de 2008. Algunos Aspectos, Cuadernos Penales José María Lidón, núm.6, Bilbao, 2009.

SCHENEIDER, Kurt, Las personalidades Psicopáticas, $8^{\mathrm{a}} \mathrm{ed}$, LLOPIS, Bartolomé (Trad.), Madrid: Morata, 1980.

TERRADILlOS BASOCO, J., Peligrosidad Social y Estado de Derecho, Madrid: Ed. Akal, 1981.

TORRUBIA BELTRI, Rafael, "La psicopatía”, en: PÉREZ, J. (Coord.), Bases Psicológicas de la delincuencia y de la conducta antisocial, Barcelona: PPU, 1987.

TORRUBIA BELTRI, Rafael y CUQUERELLA FUENTES, Ángel, "Psicopatía: una entidad clínica controvertida pero necesaria en psiquiatría forense", Revista Española de Medicina Legal 34(1) (2008).

ZUGALDÍA ESPINAR, J.M., "Medidas de seguridad complementarias y acumulativas para autores peligrosos tras el cumplimiento de la pena", en Revista de Derecho Penal y Criminología, 2009-1. 